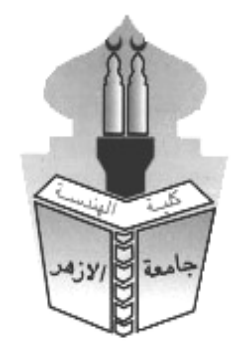

\title{
SEISMIC BEHAVIOR OF TORSIONALLY ASYMMETRIC NSC AND HSC 3-D MULTISTORY BUILDINGS
}

\author{
Doaa M. Awad*, Ahmed M. Yousef, Ahmed A. Ghaleb and Mohammed M. Adel \\ Structural Engineering Department, Faculty of Engineering, Mansoura University, \\ Mansoura, Egypt \\ *Corresponding Author E-mail: doaa.awad89@yahoo.com.
}

\begin{abstract}
The nonlinear seismic behavior of torsionally asymmetric reinforced concrete 3-D multistory buildings constructed from Normal-Strength Concrete (NSC) with characteristic cylinder compressive strength $f_{c}{ }^{\prime}=25 \mathrm{MPa}$ and from High-Strength Concrete (HSC) up to $f_{c}{ }^{\prime}=100 \mathrm{MPa}$ has been studied. In addition, the applicability of the Static Equivalent Lateral Force (SELF) methods used by the seismic codes in Europe (EC-8), in the United States (ASCE/SEI 7-16) and in Egypt (ECL-2012) have been examined when applied to torsionally asymmetric multistory buildings constructed from NSC and HSC. Inelastic dynamic analysis computer program has been used to solve the nonlinear equations of motions for two models of 3-D multistory buildings with different eccentricity (e equal to $0.10 \mathrm{~L}, 0.15 \mathrm{~L}$, and $0.20 \mathrm{~L}$ ) and constructed from NSC and HSC. Many real and artificial earthquake records with wide ranges of frequency content have been selected as input ground motions, from them two suitable earthquake records have been used in the dynamic analysis. The results showed that increasing the design concrete strength from NSC $\left(f_{c}=25 \mathrm{MPa}\right)$ to $\mathrm{HSC}\left(f_{c}=75 \mathrm{MPa}\right)$, generally decreases the average story displacement and the average story drift along the height of the models. The allowable limits of the story drift adopted by ASCE/SEI 7-16, EC-8 and ECL-2012 are conservative when applied to torsionally asymmetric NSC and HSC buildings with the studied eccentricities. The SELF method of ECL-2012 was unconservative especially for the upper stories when applied to torsionally asymmetric NSC and HSC multistory buildings with the studied different eccentricities while the SELF methods of ASCE/SEI 7-16 and EC-8 were conservative when applied to torsionally asymmetric NSC and HSC multistory buildings.
\end{abstract}

\section{KEYWORDS: Seismic Behavior, Nonlinear; Torsionally Asymmetric, High-Strength Concrete, Codes.}

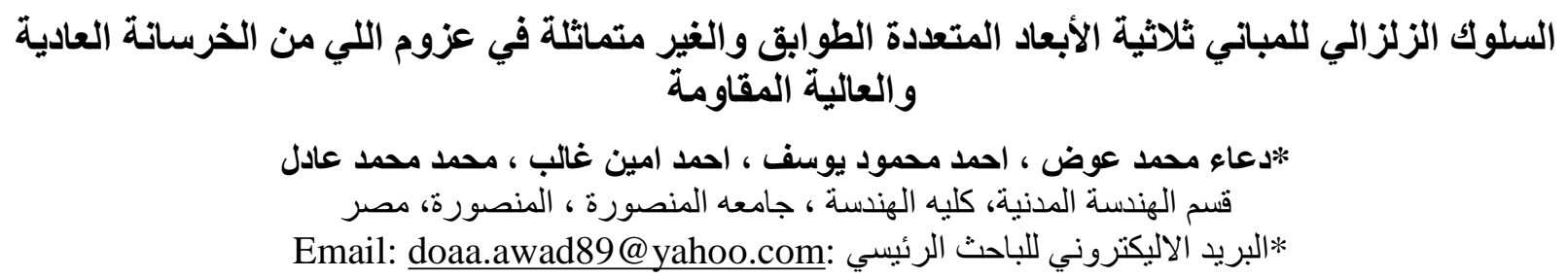

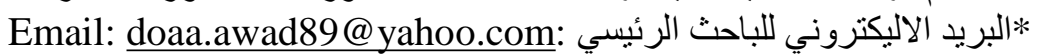

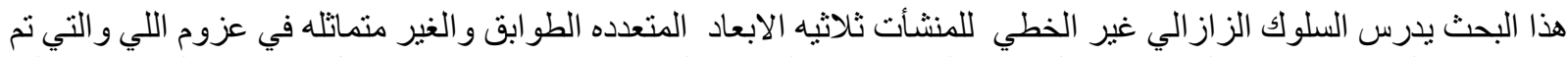

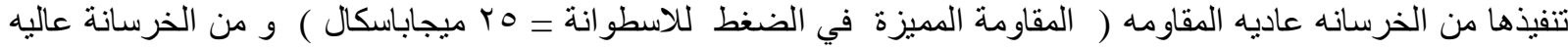




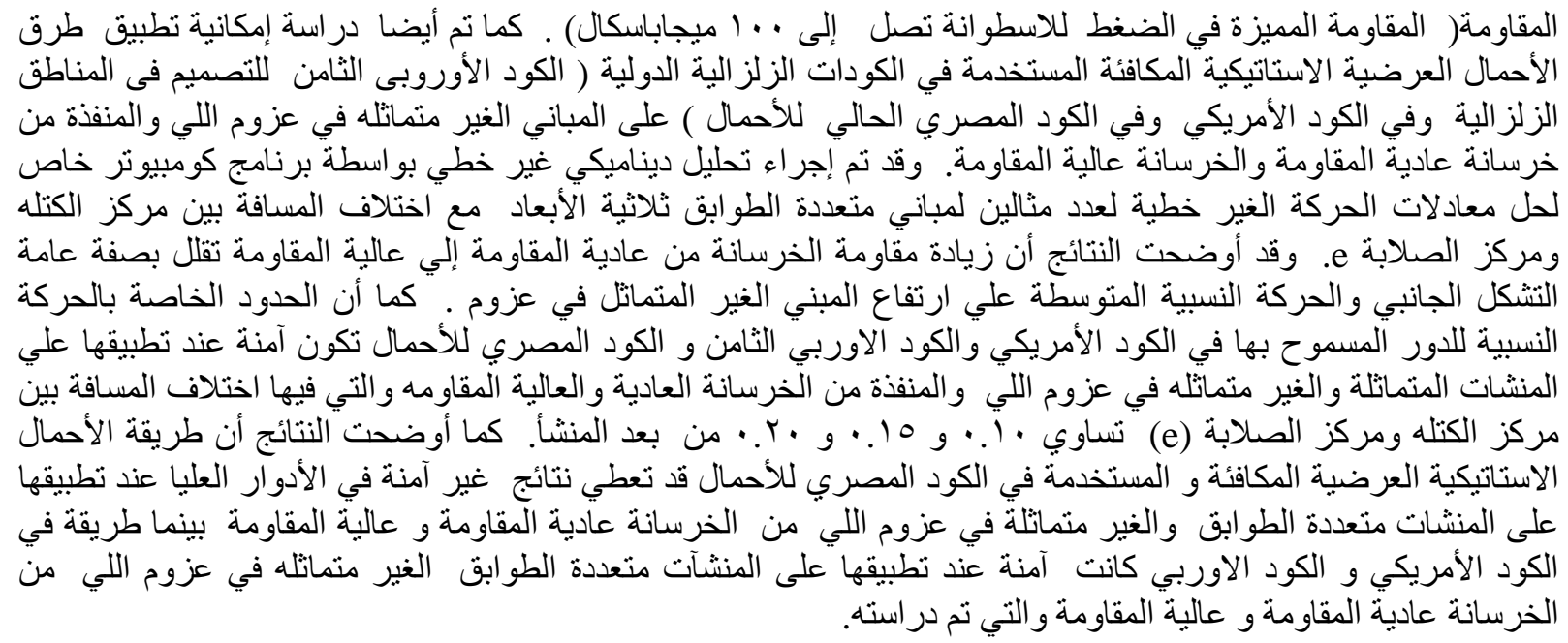

الكلمات المفتاحيه: السلوك الزلزالي، الغير خطي ، الغير متماثل في عزوم اللي ،خرسانه عاليه المقاومة،الاكواد

\section{1-INTRODUCTION}

When the center of mass and center of rigidity does not coincide, eccentricities are developed in the buildings which further generate torsion and the structure is so-called torsionally asymmetric (with horizontal irregularity). Structural irregularities may vary dramatically in their nature and, in principle, are very difficult to define. Regarding buildings, for practical purposes, major seismic international codes, in the United States, the International Building Code (IBC-2018)[1] which uses the requirements of the American Society of Civil Engineers and Structural Engineering Institute (ASCE/SEI 7-16)[2], in Europe, Eurocode 8 (EC-8) [3] and in Egypt, the Egyptian Code for Loads (ECL-2012) [4], distinguish between irregularity in plan and in elevation. Many real reinforced concrete structures are usually torsionally asymmetric since symmetrical buildings is an idealization that is very rare because of architecture or environments considerations. When these buildings are subjected to lateral loads, then the phenomenon of torsional coupling occurs due to the interaction between lateral loads and resistant forces. Torsional coupling generates greater damage in the buildings as demonstrated by many real earthquakes [5,6]. Recently, the use of HSC $\left(f_{c}^{\prime}>50 \mathrm{MPa}\right)$ has increased significantly in tall buildings due to its improved performance characteristics when compared with NSC [7]. HSC has many benefits, both in performance and cost-efficiency, so HSC advantages are a reduction in structural element size, reduction in amount of longitudinal reinforcement, decreased time necessary for concrete's formwork. Therefore, the use of HSC provides slenderer elements with lower stiffness which may lead to many questions about the seismic behavior of torsionally asymmetric R/C buildings constructed with HSC. In comparison with research efforts dealing with NSC torsionally asymmetric structures [8-13], the seismic behavior of HSC buildings is very limited in the literature [14].

The main objective of the present study is to compare the overall seismic response of torsionally, asymmetric 3-D multistory buildings constructed from NSC (with $f_{c}=25 \mathrm{MPa}$ ) and HSC (with $\boldsymbol{f}_{\boldsymbol{c}}$, up to $100 \mathrm{MPa}$ ) with different eccentricity (e equal to $0.10 \mathrm{~L}, 0.15 \mathrm{~L}$, and $0.20 \mathrm{~L}$ ). The applicability of the Static Equivalent Lateral Force (SELF) methods and the story drift limits used by the seismic codes in Europe (EC-8), in the United States (ASCE/SEI 7-16) and in Egypt (ECL-2012), have been also examined when applied to NSC and HSC torsionally asymmetric multistory buildings. 


\section{2- SELF METHODS, PERIOD OF VIBRATION EQUATIONS AND STORY DRIFT LIMITS ADOPTED BY THE SEISMIC CODES \\ 2.1 ASCE/SEI 7-16}

The total base shear $\mathrm{V}$ can be calculated using the following equation:

$V=C_{S} W$

(Where $\mathrm{Cs}$ is the seismic response coefficient, $\mathrm{W}$ is the design seismic weight of the structure ( $\mathrm{W}$ is taken equal to the total dead load and 0.25 of the live load).

$C_{S}=\frac{S_{D S}}{\frac{R}{I_{e}}}$

Where $S_{D S}$ is the design spectra response acceleration at short periods, $R$ is the response modification factor ( $R=7$ for special reinforced concrete shear walls), $I_{e}$ is the occupancy importance factors that depend on the risk category ( $I_{e}=1.0$ for risk category II).

The seismic response coefficient, $C_{S}$ not exceed the following equation:

$$
C_{S}=\frac{S_{D S}}{T\left(\frac{R}{V_{g}}\right)} \quad \text { for } T \leq T_{Z}
$$

$C_{S}=\frac{S_{D S} T_{L}}{T^{2}\left(\frac{R}{V_{e}}\right)} \quad$ for $T>T_{L}$

$C_{S}$ shall not be less than:

$C_{S}=0.044 S_{D S} I_{e} \geq 0.01$

For structures located where $S_{l}$ is equal to or greater than $0.6 \mathrm{~g}, C_{S}$ shall be not less than:

$$
C_{S}=\frac{0.5 S_{1}}{\frac{R}{I_{\theta}}}
$$

Where $S_{D_{1}}$ is the design spectra response acceleration at a period of $1.0 \mathrm{~s}, T_{L}$ is the long period transition period (s), $T_{\bar{L}}$ the mapped maximum considered earthquake spectral acceleration parameter and $\mathrm{T}$ is the fundamental period of vibration of response the structure and can be calculated from the following equation:

$$
T=C_{t}\left(h_{n}\right)^{x}
$$

where $\boldsymbol{h}_{n}$ is the total height of the building and $C_{t}$ is a factor range from 0.0466 to 0.0731 , while $\mathrm{x}$ varies from 0.75 to 0.9 according to structure type, $C_{t_{t}}=0.0488$ and $\mathrm{x}=0.75$ (for all structure systems).

The design spectral response acceleration at a short period $S_{D s}$ :

$$
S_{D S}=\frac{2}{3} F_{a} S_{S}
$$

The design spectral response acceleration at one second period $S_{D S}$ :

$$
S_{D S}=\frac{2}{3} F_{V} S_{1}
$$

Where the values of $F_{a}$ and $F_{V}$ (site coefficient) according to site class D and spectral response acceleration parameters $S_{S}$ and $S_{\mathbf{1}}$.

The base shear $\mathrm{V}$ is distributed over the height of the building according to: 
$F_{\text {Story }}=\frac{V W_{\text {Story }} \boldsymbol{h}^{k} \text { story }}{\mathbf{\Sigma} W_{\text {Story }} \boldsymbol{h}^{k} \text { story }}$

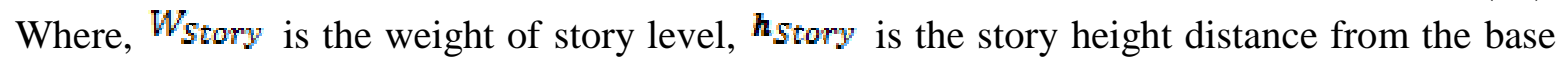
of the structure to story level and $\mathrm{k}$ is exponent applied to building height. The value of $\mathrm{k}$ depends on the value of the building period, $\mathrm{T}$, used for determining the base shear. If $\mathrm{T} \leq 0.5$ seconds, $\mathrm{k}=1$. If $\mathrm{T} \geq 2.5$ seconds, $\mathrm{k}=2$. If $0.5<\mathrm{T}<2.5$ seconds, $\mathrm{k}$ is linearly interpolated between 1 and 2 .

According to this code, the allowable story drift taking into account the life-safety and damage control objective which limited as follows:

For structures in risk category I or II:

$\Delta_{a}=0.02 h_{s x}$

For risk category III:

$\Delta_{a}=0.015 h_{5 x}$

, and for IV:

$\Delta_{a}=0.01 h_{s x}$

Where $\boldsymbol{h}_{5 x}$ is the story height below level x.

\subsection{EC-8}

The total base shear $\mathrm{V}$ can be calculated using the following equation:

\section{$F_{b}=S_{a}(T) W \lambda$}

Where $S_{d}(T)$ is the ordinate of the elastic design response spectrum given by the code for the fundamental period of the building, $W$ is the design seismic weight of the structure as recommended in this code and $\lambda$ is the correction factor $\lambda=0.85$ if $T \leq 2 T_{C}$ and the building has more than two stories or $\lambda=\mathbf{1}$ otherwise.

The design response spectrum $S_{d}(\mathrm{~T})$ shall be determined as follows:

$$
\begin{aligned}
& \text { if } 0<T<T_{B} \quad S_{d}(T)=a_{g} \cdot s\left[\frac{2}{3}+\frac{T}{T_{B}}\left(\frac{2.5}{q}-\frac{2}{3}\right)\right] \\
& \text { if } T_{B}<T<T_{C} \quad S_{d}(T)=a_{g} \cdot S\left[\frac{2.5}{q}\right] \\
& \text { if } T_{C}<T<T_{D} \quad S_{d}(T)=a_{g} \cdot s \frac{2.5}{q}\left[\frac{T_{c}}{T}\right] \\
& \geq \beta a_{g} \\
& \text { if } T_{D}<T_{1}<4.0 \mathrm{sec} \quad S_{d}(T)=a_{g} \cdot s \frac{2.5}{q}\left[\frac{T_{c} T_{D}}{T_{\mathbf{1}}{ }^{2}}\right] \\
&
\end{aligned}
$$

where $S_{d}(T)$ is the ordinate of the design spectrum for the reference return period and limited to gravity acceleration, $\mathbf{a}_{\square}$ is the design ground acceleration on type A ground $\mathbf{a}_{\mathrm{g}}=\gamma \mathbf{a}_{\mathbb{E R}}, \mathrm{S}$ is the soil factor, $\beta$ is lower bound factor the horizontal design spectra ( $\beta=0.2), T_{B}$ and $T_{C}$ are the constant limits for elastic response spectrum, $T_{D}$ is the limit value for the start of constant displacements of the spectrum and $\mathrm{T}$ is the fundamental period of vibration of the building and shall be determined from: 


$$
T=C_{t} H^{\frac{3}{4}}
$$

$C_{t}$ is equal to 0.075 for space reinforced concrete frames and equal 0.05 for dual systems, $q$ is the behavior factor ( $\mathrm{q}={ }^{\top}$ for R.C dual systems).

The calculated base shear shall be distributed over the height of the building in conformance with the following equation:

$$
F_{i}=F_{b} \frac{w_{i} \boldsymbol{h}_{i}}{\boldsymbol{\Sigma}_{j=1}^{n} w_{j} \boldsymbol{h}_{j}}
$$

The story drift $d r$ should be limited as follows:

For buildings having non-structural elements of brittle materials attached to the structure (such as unreinforced masonry):

$d_{n} \leq 0.005 h v$

For buildings having non-structural elements of ductile materials:

$d_{r} \leq 0.0075 \mathrm{hv}$

For buildings having non-structural elements fixed in a way that does not interfere with structural deformations:

$d_{r} \leq 0.001 \mathrm{hv}$

where $v$ is a reduction factor equal to 2.5 and 2.0 for importance categories (I, II) and (III, IV), respectively.

2.3 ECL-2012

The provision of ECL-2012 is similar to that of EC-8. The total base shear $F_{b}$ can be calculated as follows:

$\left.F_{b}=s_{d} T_{1}\right) \frac{W}{g}$

Where $\mathrm{W}$ is the equivalent structure weight and $S_{d}\left(T_{1}\right)$ is the design response spectrum and shall be determined as follows:

$$
\begin{aligned}
& \text { if } 0<T_{1}<T_{B} \quad S_{d}\left(T_{1}\right)=a_{g} \gamma_{1} . S\left[\frac{2}{3}+\frac{T_{1}}{T_{B}}\left(\frac{2.5 \eta}{R}-\frac{2}{3}\right]\right. \\
& \text { if } T_{B}<T_{1}<T_{C} \quad S_{d}\left(T_{1}\right)=a_{g} \cdot \gamma_{1} S\left[\frac{2.5 \eta}{R}\right] \\
& \text { if } T_{C}<T<T_{D} \quad S_{d}\left(T_{1}\right)=a_{g} \cdot \gamma_{1} S \frac{2.5 \eta}{R}\left[\frac{T_{c}}{T_{1}}\right] \eta \\
& \geq 0.20 a_{g} \gamma_{1} \\
& \text { if } T_{D}<T_{1}<4.0 \mathrm{sec} \quad S_{d}\left(T_{1}\right)=a_{g} \gamma_{1} \cdot S \frac{2.5}{R}\left[\frac{T_{c} T_{D}}{T_{1}{ }^{2}}\right] \eta \\
& \geq 0.2 a_{g} \gamma_{1}
\end{aligned}
$$

where $a_{g}$ is the design ground acceleration, $T$ is the fundamental period of the building and shall be determined from Eq. (19), $\mathrm{H}$ is the total height of the building, $T_{B}$ and $T_{C}$ are the constant limits for elastic response spectrum, $T_{D}$ is the limit value for the start of a displacement of the spectrum, $\mathrm{R}$ is the response modification factor according to the structural system $(\mathrm{R}=5$ for R.C. dual system) and $\eta$ is the damping design factor ( $\eta=1$ for RC Structure).

The calculated base shear shall be distributed over the height of the building in conformance with Eq. (20). The limits of the story drift $d_{r}$ are similar to that given in EC-8.

\section{ANALYTICAL MODELING}

The finite element computer program ETABS-17.1) $[15,16]$ was used to calculate the story displacement, story drift and story shear of 3-D building examples of the present study. In this program, the structure is modeled as a 3-D assemblage of elements connected by a finite number 
of deformable elements, or members. The effect of axial force on yield moment was considered for each column. The P- $\boldsymbol{\Delta}$ effects are included. Shear and axial deformations are neglected. The structure mass is lumped at the nodes, and the mass matrix is diagonal. The stiffness properties of individual members are controlled by the rules of the Takeda hysteresis model [17]. The damping matrix was expressed as a linear combination of the mass and stiffness matrices, and the coefficients were selected to give $5 \%$ of critical damping in the first two vibrational modes. The differential equation of motion is formulated in incremental form and integrated using a smalltime interval. For NSC and for HSC in compression, the model suggested by Daniel and Patrick [18] is adopted. This model neglected the effect of confinement on concrete strength. For this model, the value of the strain at a maximum strength of unconfined concrete is taken equal to 0.002 and the value of the strain for half of the maximum strength of unconfined concrete is taken equal to 0.004 . The modulus of elasticity for NSC and HSC can be calculated using the equations recommended by the ACI 318-14 building code [19] and the ACI Committee 363 [7], respectively. For concrete in tension, the model used by Massicotte et al. [20] is adopted. This model can be expressed by three linear parts defined by the slope of the line and the calculated value of the tensile strength of concrete $f_{t}$. For NSC and HSC, $f_{t}$ can be calculated, respectively, from the equations suggested in references [19] and [7]. For the steel reinforcement bars, a trilinear stress-strain relationship is adopted. The modulus of elasticity of the steel bars is taken equal to $200 \mathrm{KN} / \mathrm{mm}^{2}$. The adopted model of pullout for the steel bars is that suggested by Fillippou et al. [21].

\section{INPUT EARTHQUAKE RECORDS}

In this study, the seismic analyses have been carried out using two different earthquake records. The first earthquake record is the Imperial Valley North-South component of the 1940 EL Centro (peak ground acceleration $(\mathrm{PGA}=0.35 \mathrm{~g}$ ). The acceleration time history of this earthquake is shown in Fig. 1. This was chosen from four different earthquake records (El-Centro, Parkfield, New Mexico, and San Fernando) to match the "highest design level" earthquakes in the United States according to the ASCE/SEI 7-16 and in Europe according to EC-8 (regions of ductility class "High" required by EC-8). The second earthquake is an artificial earthquake record having peak ground acceleration of $0.3 \mathrm{~g}$ and duration of 20 seconds and is chosen to represent the "probable design level" earthquakes for zone 5b in Egypt according to the ECL-2012. A response spectrum shape for soil type C (dense or medium-dense sand, gravel or stiff clay soils) with damping ratio 5\% according to the ECL-2012 was taken as the target spectrum for this artificial earthquake. Twelve artificial acceleration time histories for different percentages of spectral values (Sv\%) were generated using the computer program SIMQKE [22]. In order to choose the "Moderate Earthquake" as required by the ECL-2012, a time history analysis of Example 1 and 2 using these artificial earthquakes and the N-S component of El-Centro earthquake were compared. The artificial earthquake with $(33 \% \mathrm{~Sv})$ shown in Fig. 2 can be considered as that suitable for zone $5 \mathrm{~b}$ in Egypt. The generated and target response spectra for this artificial earthquake are shown in Fig. 3.

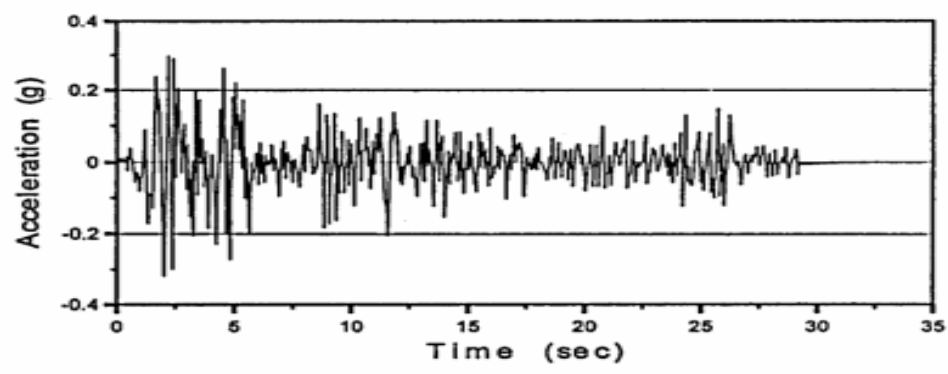

Fig. 1. Acceleration time history for N-S component of El Centro 1940 earthquake. 


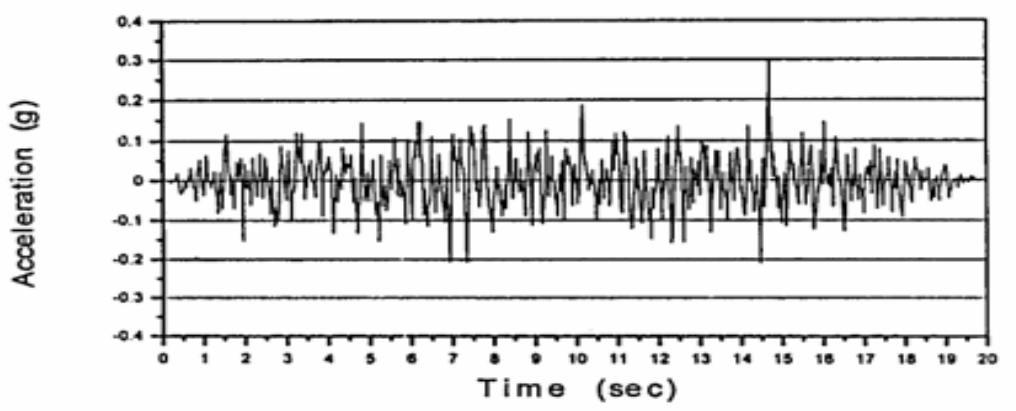

Fig. 2. Acceleration time history for the artificial earthquake of zone $5 \mathrm{~b}$ in Egypt.

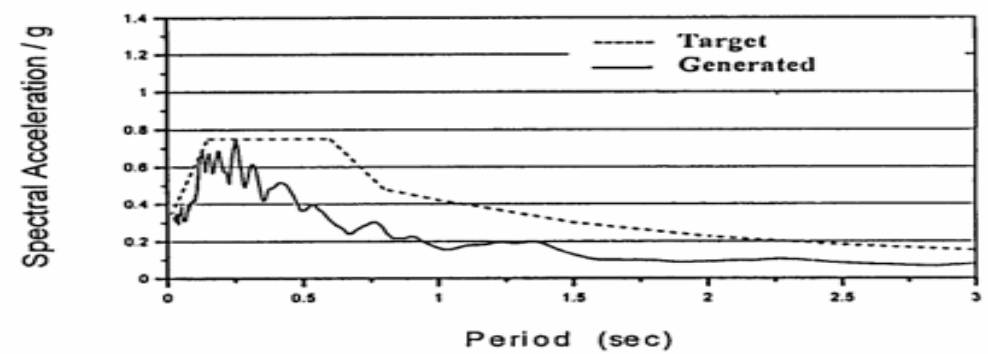

Fig. 3. Generated and target response spectra for the artificial earthquake.

\section{3-BUILDING EXAMPLES}

Two examples of reinforced concrete 3D multistory asymmetric buildings were used in the analysis of this study. The first example consists of one 12-story ductile moment-resisting frame and two 12-story dual systems as shown in Fig. 4. Table 1 describes the dimensions and details of the frames and the dual system of this example [23]. The columns, beams and shear walls of this example for the different cases (NSC with $f c^{\prime}=25 \mathrm{MPa}$, HSC with $f c^{\prime}=75 \mathrm{MPa}$ and VHSC with $f c^{\prime}=100 \mathrm{MPa}$ ) were designed according to the requirements of ACI 318-14 building code [19]. Longitudinal steel bars with yield strength equal to $400 \mathrm{MPa}$ were used for all the members of this example. This example was analyzed under earthquake time histories in the horizontal direction (Y-axis). In this example, the shown shear wall $\mathrm{W} 1$ was kept constant while the dimensions of the second shear wall W2 was changed to get the required eccentricity (e). For each case changing the width of shear wall $\left(\mathrm{W}_{2}\right)$ changed the eccentricity of the building example. The studied eccentricities $(\mathrm{e}=0.10 \mathrm{~L}, 0.15 \mathrm{~L}$ and $0.20 \mathrm{~L})$ were chosen in order to study the limit determined by ECL-2012 to distinguish torsionally regular from irregular multistory buildings. It should be noted that according to ECL-2012 the building with $\mathrm{e} / \mathrm{L} \leq 0.15$ is considered as torsionally regular while for $\mathrm{e} / \mathrm{L}>0.15$ the building is considered as torsionally irregular.

The second example is twelve stories asymmetric building has square in plan with dimensions $(25 \mathrm{~m} \times 25 \mathrm{~m})$ with a symmetrical plan arrangement in columns and shear walls as shown in Fig. 5. The slab is a flat slab of thickness equal to $18 \mathrm{~cm}$. the marginal beam of all floors is $\left(25^{*} 70\right)$ $\mathrm{cm}$. Table 2 shows columns and shear walls dimensions [8]. The place of the left shear wall remains constant in plan without change, while the place of the right shear wall $\mathrm{W}_{\mathrm{R}}$ is changed to get the studied eccentricity e. It should be noted that the place of the right shear wall $\mathrm{W}_{\mathrm{R}}$ is changed by a distance equal to $2.5 \mathrm{~m}$ to the right to get the case of e/L $=0.05$ and additional 2.5 $\mathrm{m}$ to get the case of e/L $=0.10$, and so on.

For each example, two cases (Case-I and Case-II) were considered under the horizontal N-S component of El Centro 1940 and the artificial earthquake record of Egypt. In Case-I, the crosssections of the columns, beams and shear walls of the first story of the building example were designed using NSC (with $f c^{\prime}$ equal to $25 \mathrm{MPa}$ ) and reduced the cross section along the height of 
building. Three values of the design concrete strength were considered without changing the cross-sections of the building example (NSC with $f c^{\prime}$ equal to $25 \mathrm{MPa}$, HSC with $f c^{\prime}$ equal to 75 $\mathrm{MPa}$ and VHSC with $f c^{\prime}$ equal to $100 \mathrm{MPa}$ ). In Case-II, the cross-sections of the building example were changed according to the variation of the design concrete strength. It should be noted that the first part of the symbols shown in the following figures refers to the case condition (I: Case- I and II: Case-II). The second part refers to the design concrete strength (N: NSC = 25 $\mathrm{MPa}, \mathrm{H}: \mathrm{HSC}=75 \mathrm{MPa}$ and $\mathrm{VH}: \mathrm{VHSC}=100 \mathrm{MPa})$ and the third part refers to the studied concrete strength. All the cases analyzed with different static eccentricity (e) $0.0 \mathrm{~L}, 0.10 \mathrm{~L}, 0.15 \mathrm{~L}$, and $0.20 \mathrm{~L}$.

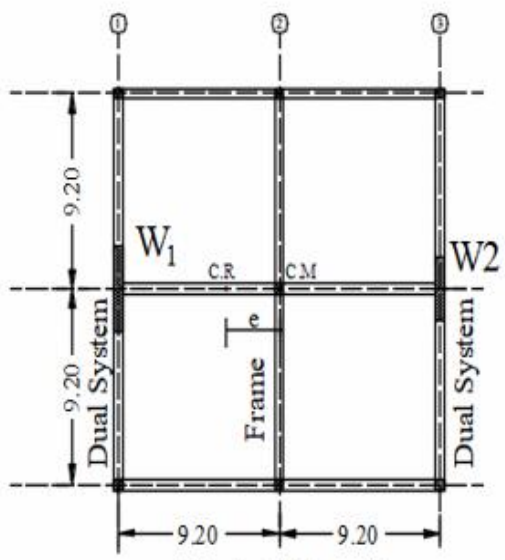

Typical Floor Plan
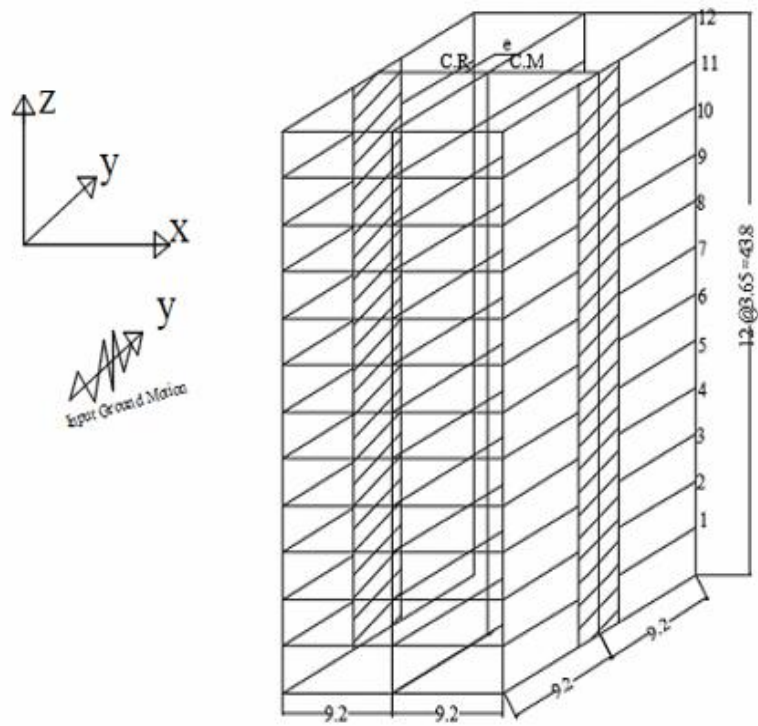

Typical Isometric

Fig. 4. Configuration of 3-D torsionally asymmetric building Example-1.

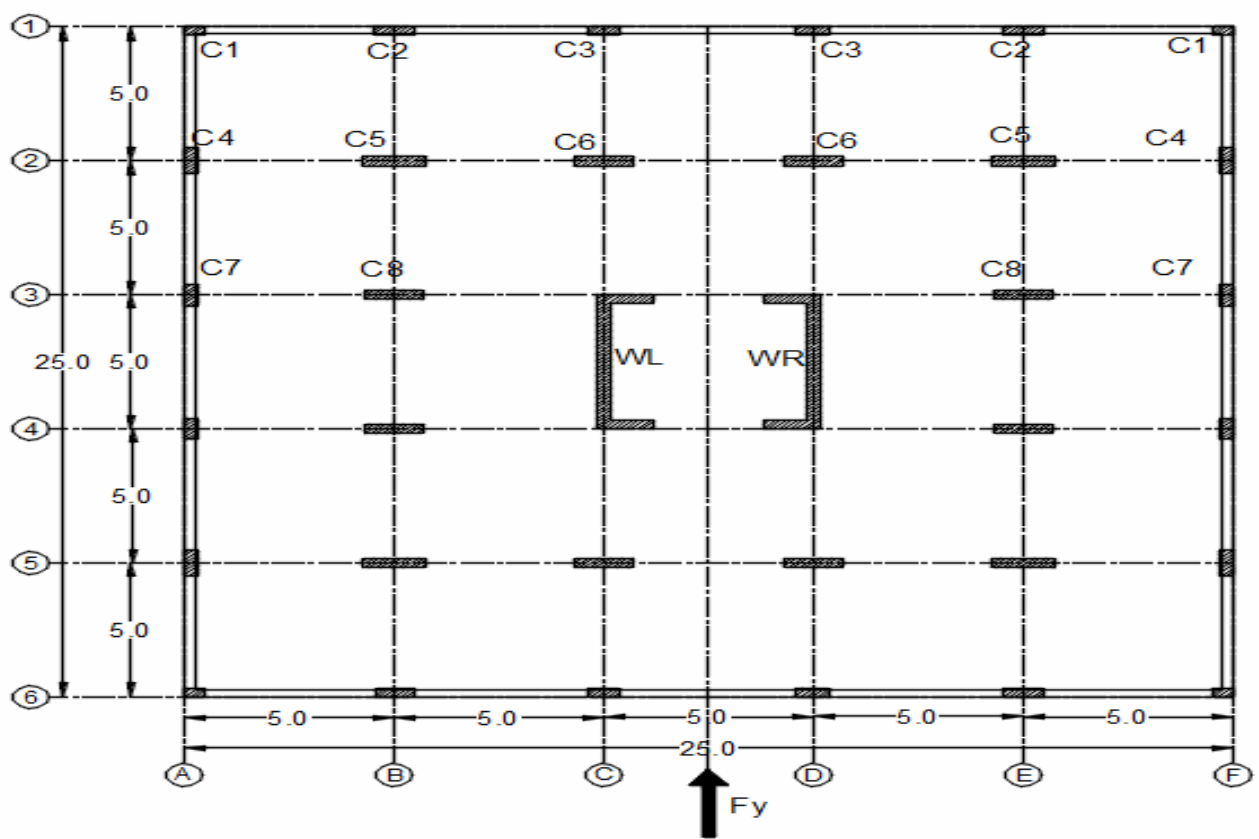

Fig. 5. Plan of typical 3-D torsionally asymmetric building Example-2. 
SEISMIC BEHAVIOR OF TORSIONALLY ASYMMETRIC NSC AND HSC 3-D MULTISTORY BUILDINGS

Table 1. Principal data for 3-D building Example-1

\begin{tabular}{|c|c|c|c|}
\hline Principal Data & $\begin{array}{c}\mathrm{NSC} \\
t^{*} \mathrm{bmm}\end{array}$ & $\begin{array}{c}\mathrm{HSC} \\
\mathrm{t} * \mathrm{bmm} \\
\end{array}$ & $\begin{array}{l}\text { VHSC } \\
t^{*} b \mathrm{~mm}\end{array}$ \\
\hline \multirow{2}{*}{\multicolumn{4}{|c|}{$\begin{array}{l}\text { 12-Story Frame } \\
\text { Size of Main Beams }\end{array}$}} \\
\hline & & & \\
\hline 1-6 Floor & $750 * 400$ & $700 * 300$ & $650 * 300$ \\
\hline 7-8 Floor & $700^{*} 400$ & $650 * 300$ & $600 * 300$ \\
\hline 9-10 Floor & $650 * 400$ & $600 * 300$ & $550 * 300$ \\
\hline 11-12 Floor & $600 * 400$ & $550 * 300$ & $500 * 300$ \\
\hline \multicolumn{4}{|l|}{$\underline{\text { Size of Exterior Columns }}$} \\
\hline 1-3 Floor & $725 * 500$ & $700 * 350$ & $650 * 300$ \\
\hline 4-6 Floor & $625 * 500$ & $600 * 350$ & $650 * 300$ \\
\hline 7.8 Floor & $575 * 500$ & $550 * 350$ & $500 * 300$ \\
\hline 9-10 Floor & $525 * 500$ & $500 * 350$ & $450 * 300$ \\
\hline 11-12 Floor & $500 * 500$ & $450 * 350$ & $400 * 300$ \\
\hline \multicolumn{4}{|l|}{ Size of Interior Columns } \\
\hline 1-3 Floor & $725 * 725$ & $625 * 625$ & $600 * 600$ \\
\hline 4-6 Floor & $675 * 675$ & $575 * 575$ & $525 * 525$ \\
\hline 7.8 Floor & $625 * 625$ & $525 * 525$ & $475 * 475$ \\
\hline 9-10 Floor & $575 * 575$ & $475 * 475$ & $450 * 450$ \\
\hline 11-12 Floor & $550 * 550$ & $450 * 450$ & $400 * 400$ \\
\hline \multicolumn{4}{|l|}{$\begin{array}{l}\text { 12-Story Dual system } \\
\text { Size of Main Beams }\end{array}$} \\
\hline 1.6 Floor & $850 * 250$ & $700 * 250$ & $650 * 250$ \\
\hline 7-12 Floor & $750 * 250$ & $650 * 350$ & $600 * 250$ \\
\hline Size of Exterior Columns & $400 * 400$ & $350 * 350$ & $325 * 325$ \\
\hline \multicolumn{4}{|l|}{ Size of Shear Wall } \\
\hline w1 & $4000 * 250$ & $4000 * 250$ & $4000 * 250$ \\
\hline \multirow{3}{*}{ W2 } & $3000 * 250$ & $3000 * 250$ & $3000 * 250$ \\
\hline & $3300 * 250$ & $3300 * 250$ & $3300 * 250$ \\
\hline & $3500 * 250$ & $3500 * 250$ & $3500 * 250$ \\
\hline
\end{tabular}


SEISMIC BEHAVIOR OF TORSIONALLY ASYMMETRIC NSC AND HSC 3-D MULTISTORY BUILDINGS

'Table 2. Principal Data For 3-D Building Example-2

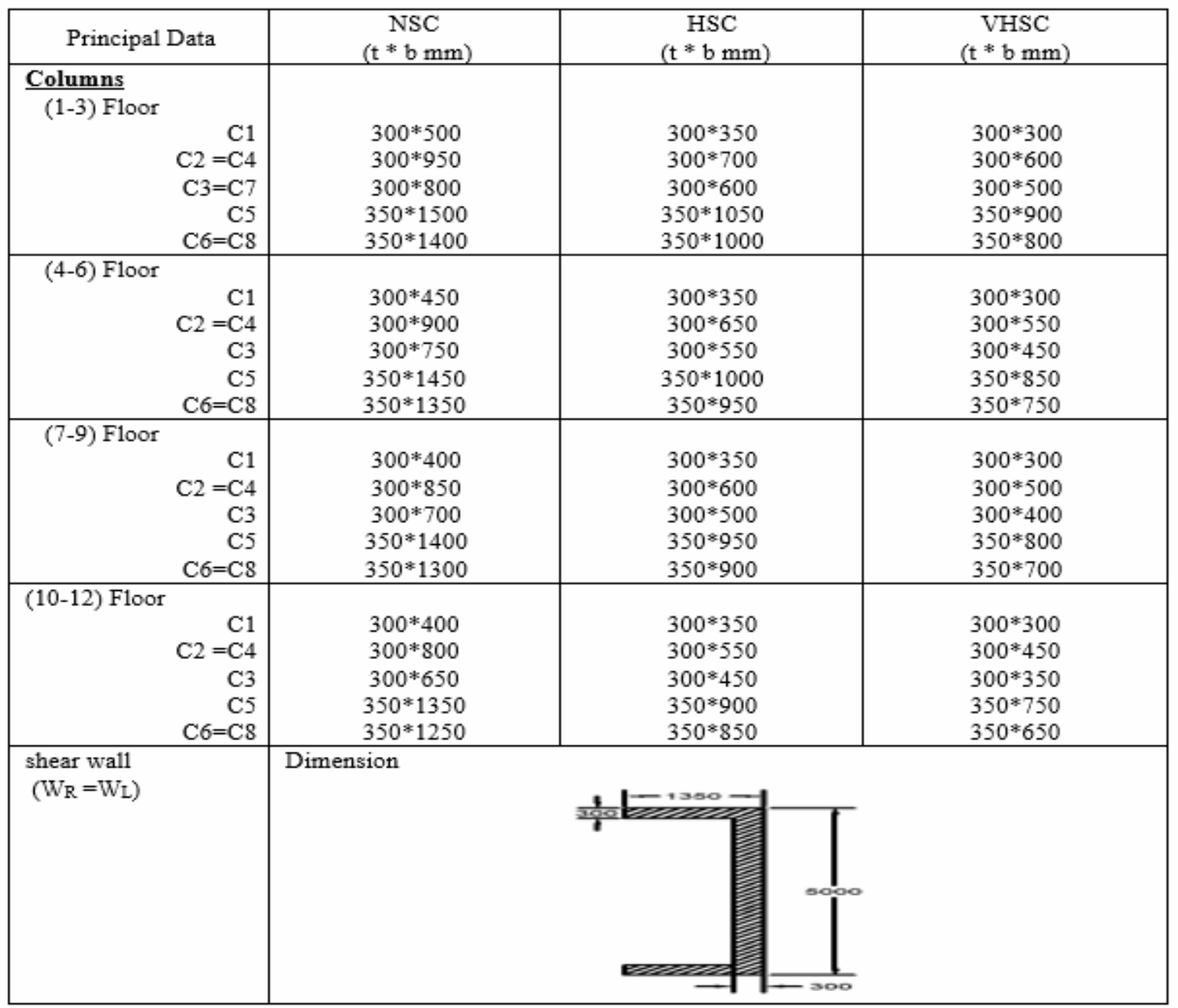

\section{4- OVERALL RESPONSE OF TORSIONALLY ASYMMETRIC NSC AND HSC 3-D MULTISTORY BUILDINGS}

\subsection{Effect of Concrete Strength on the Story Displacement and Story Drift}

The envelopes of the story drift along the height of the building Example-1 due to the variation of the concrete strength for Case-I and Case-II under N-S component of EL Centro 1940 earthquake and the artificial earthquake of Egypt for different e/L ratio as shown in Fig. 6 to 9. Increasing the actual concrete strength from NSC to HSC generally reduced the average story displacement and also the story drift along the height of the building for different e/L ratios. For Case-II, it can be seen that for (e/L) equal to 0.0, increasing the concrete strength from NSC to HSC resulted in a reduction in the average story drift by $32.14 \%$, while increasing the concrete strength from HSC to VHSC resulted in growth about $1.72 \%$. For $(\mathrm{e} / \mathrm{L})$ equal to 0.10 , increasing the concrete strength from NSC to HSC resulted in a reduction in the average story drift by $32.14 \%$, while increasing the concrete strength from HSC to VHSC resulted in a reduction by about $4.52 \%$. For $(\mathrm{e} / \mathrm{L})$ equal to 0.15 , the ratio of the reduction of the average story drift became $33.15 \%$ when increasing the concrete strength from NSC to HSC, while for $(\mathrm{e} / \mathrm{L})$ equal 0.20 the reduction value became $30.34 \%$. Under the artificial earthquake, the reduction in the story drift due to increasing the concrete strength was relatively small compared with that resulted from the El-Centro earthquake. This was due to the low-frequency content of the artificial earthquake. 
The envelopes of the story drift along the height of the building Example-2 due to the variation of the concrete strength for Case-I and Case-II under N-S component of EL-Centro 1940 earthquake and the artificial earthquake of Egypt are shown in Figs.10 to 13 for different e/L ratio. Increasing the actual concrete strength from NSC to HSC generally reduced the average story drift along the height of the building for different e/L ratio. For Case-II, it can be seen that for (e/L) equal to 0.0, increasing the concrete strength from NSC to HSC resulted in a reduction in the average story drift by $32.17 \%$, while increasing the concrete strength from HSC to VHSC resulted in a reduction by about $15.86 \%$. For (e/L) equal to 0.10 , increasing the concrete strength from NSC to HSC resulted in a reduction in the average story drift by $34.14 \%$, while increasing the concrete strength from HSC to VHSC resulted in a reduction by about $13.17 \%$. For (e/L) equal to 0.15 , the ratio of the reduction of the average story drift became $26.51 \%$ when increasing the concrete strength from NSC to HSC, while for (e/L) equal 0.20 the reduction value became $20.41 \%$. Under the artificial earthquake, the reduction in the story drift due to increasing the concrete strength was relatively small compared with that resulted from El-Centro earthquake. In general, the overall response of the story drift for Example-2 for Case-I and case-II along the height of the building is similar to that of the lateral displacement under El-Centro earthquake and also under the artificial earthquake of Egypt for different e/L ratio.

Tables 3 and 4 show a comparison between the maximum values of the story drift required by ASCE/SEI 7-16, EC-8 and ECL-2012 due to the variation of the concrete strength with the envelopes of the story drift of Example-1 and Example-2 for Case-I and Case-II under N-S component of EL Centro 1940 earthquake and artificial earthquake record with different (e/L) ratio $0.10,0.15$ and 0.20 . For the nonlinear time history analysis, the mean story drift shall not exceed two times the limits of SELF method of ASCE/SEI 7-16 code.

It can be seen that the limit of ASCE/SEI 7-16 and EC-8 codes are considerably conservative for NSC, HSC and VHSC buildings for the two examples with different (e/L) ratios. Comparing the maximum values of the story drift allowed by the ECL-2012 with the envelopes of the story drift of the studied examples under the artificial earthquake record showed that this limit is conservative for NSC, HSC and VHSC buildings for the two cases with different (e/L) ratio.

\subsection{Effect of Concrete Strength on the Story Shear}

The envelopes of the story shear along the height of the building Example-1 due to the variation of the concrete strength for Case-I and Case-II under N-S component of EL Centro 1940 earthquake and the artificial earthquake of Egypt are shown in Tables 5 to 8 for different e/L ratio. For Case-I, it can be seen that increasing the concrete strength from NSC to HSC resulted in a reduction in the average story shear by about $1.89 \%, 9.73 \%, 9.95 \%$, and $9.31 \%$, when $(\mathrm{e} / \mathrm{L})$ equal to $0.0,0.10,0.15$ and 0.20 , respectively, while increasing the concrete strength from HSC to VHSC increased the average story shear by $6.44 \%, 3.34 \%, 2.05 \%$, and $2.65 \%$, respectively. The trend of the story shear due to increasing the concrete strength for this case is not clear. This seems to be due to higher modes effect of EL-Centro earthquake.

For Case-II, it can be seen that when (e/L) equal to 0.0, 0.10, 0.15 and 0.20 , increasing the design concrete strength from NSC to HSC resulted in a reduction in the average story shear by $28.24 \%$, $30.43 \%, 30.60 \%$, and $25.55 \%$, respectively, while increasing the concrete strength from HSC to VHSC decreased the average story shear by relatively small values $4.28 \%, 6.41 \%, 6.83 \%$ and $8.94 \%$, respectively. This showed that the reduction of the cross-sections of the building example due to increasing the design concrete strength resulted in a considerable reduction in the story shear. The reduction rate became very low when increasing the concrete strength from HSC to VHSC.

For Case-I, under the artificial earthquake in Egypt, increasing the concrete strength from NSC to HSC resulted in a growth in the average story shear by $6.79 \%, 31.70 \%, 37.14 \%$ and $49.01 \%$ when (e/L) equal to $0.0,0.10,0.15$ and 0.20 , respectively, while increasing the concrete strength from HSC to VHSC decreased the average story shear by $2.77 \%, 4.14 \%, 4.85 \%$ and $1.62 \%$, respectively. For Case-II, under the artificial earthquake in Egypt, increasing the concrete strength from NSC to HSC, for the studied e/L ratio, resulted in a reduction in the average story 
shear by $39.20 \%, 33.72 \%, 34.29 \%$ and $32.27 \%$, respectively, while increasing the concrete strength from HSC to VHSC decreased the average story shear by $3.43 \%, 4.06 \%, 5.19 \%$ and $2.78 \%$, respectively. In general, under the artificial earthquake, the story shear was relatively small compared with that resulted from the El-Centro earthquake. This was due to the lowfrequency content of the artificial earthquake.

The envelopes of the story shear along the height of the building Example-2 due to the variation of the concrete strength for Case-I and Case-II under N-S component of EL Centro 1940 earthquake and the artificial earthquake of Egypt are given in Tables 9 to 12 for different e/L ratio. For Case-I, it can be seen that increasing the concrete strength from NSC to HSC resulted in a growth of the average story shear by about $16.84 \%, 11.78 \%, 8.53 \%$, and $22.08 \%$, when (e/L) equal to $0.0,0.10,0.15$ and 0.20 , respectively, while increasing the concrete strength from HSC to VHSC decreased the average story shear by $4.25 \%, 8.05 \%, 4.90 \%$, and $10.43 \%$, when (e/L) equal to0.0, $0.10,0.15$ and 0.20 respectively. The trend of the story shear due to increasing the concrete strength for this case is not clear. This seems to be due to the higher modes effect of the EL-Centro earthquake.

For Case-II, it can be seen that the envelopes of the story shear along the height of the building Example-2 due to the variation of the concrete strength for Case-II is approximately similar to Case-I. When (e/L) equal to $0.0,0.10,0.15$ and 0.20 , increasing the design concrete strength from NSC to HSC resulted in a growth in the average story shear by $12.94 \%, 9.19 \%, 6.03 \%$ and $17.76 \%$, respectively, This showed that the reduction of the cross-sections of the building example due to increasing the design concrete strength resulted in a considerable growth in the story shear. The response of the average story shear under the artificial earthquake in Egypt is the same of N-S component of EL Centro 1940 earthquake .while increasing the concrete strength from NSC to HSC resulted in a growth in the average story shear by $13.43 \%, 11.06 \%, 22.39 \%$ and $28.83 \%$ when $(\mathrm{e} / \mathrm{L})$ equal to $0.0,0.10,0.15$ and 0.20 , respectively, while increasing the concrete strength from HSC to VHSC decreased the average story shear by4.05\%, $2.71 \% 0.21 \%$ and $4.96 \%$, respectively. For Case-II, under the artificial earthquake in Egypt, increasing the concrete strength from NSC to HSC, for the studied e/L ratio, resulted in a growth in the average story shear by $9.05 \%, 7.31 \%, 20.55 \%$ and $21.16 \%$, respectively, while increasing the concrete strength from HSC to VHSC decreased the average story shear by $6.15 \%, 1.26 \%, 5.97 \%$ and $2.41 \%$, respectively. In general, under the artificial earthquake, the story shear was relatively small compared with that resulted from the El-Centro earthquake. This was due to the lowfrequency content of the artificial earthquake. The trend of the story shear due to increasing the concrete strength is not clear.

\section{5-EFFECT OF ECCENTRICITY RATIO ON THE OVERALL RESPONSE}

\subsection{Effect of (e/L) Ratio on the Story Drift}

As shown from Figs. 6 to 12 , increasing the eccentricity ratio (e/L), generally increased the story drift along the height of the building for different concrete strength for the two Examples. From Fig. 6 and Fig. 7, it can be seen that, for Case-I of Example-1, Increasing the eccentricity ratio (e/L) from 0.0 to 0.10 resulted in a growth of the average story drift by about $28.81 \%, 11.80 \%$ and $26.12 \%$ for NSC, HSC and VHSC respectively, while increasing the eccentricity ratio (e/L) from 0.10 to 0.15 resulted in a growth of the average story drift by about $6.75 \%, 3.97 \%$ and $0.74 \%$ for NSC, HSC and VHSC respectively, while increasing the eccentricity ratio (e/L) from 0.15 to 0.20 resulted in a growth of the average story drift by about $2.73 \%, 10.81 \%$ and $1.32 \%$ for NSC, HSC and VHSC respectively. For Case-II, it can be seen that, increasing the eccentricity ratio (e/L) from 0.0 to 0.10 resulted in a growth of the average story drift by about $28.81 \%, 20.37 \%$ and $24.91 \%$ for NSC, HSC and VHSC respectively, while increasing the eccentricity ratio $(\mathrm{e} / \mathrm{L})$ from 0.10 to 0.15 resulted in a growth of the average story drift by about $6.75 \%, 5.15 \%$ and $5.10 \%$ for NSC, HSC and VHSC respectively. Increasing the eccentricity ratio (e/L) from 0.15 to 0.20 resulted in a growth of the average story drift by about $2.73 \%, 7.05 \%$ and $7.24 \%$ for NSC, HSC, and VHSC respectively. Under the artificial earthquake of Egypt for Case- 
I and Case-II, for Example-1, increasing the eccentricity ratio (e/L), generally increased the story drift along the height of the building for different concrete strength with a similar response as that under El Centro earthquake. For Case-II, it can be seen that, increasing the eccentricity ratio (e/L) from 0.0 to 0.10 resulted in a growth of the average story drift by about $10.11 \%, 38.70 \%$ and $14.23 \%$ for NSC, HSC and VHSC respectively, while increasing the eccentricity ratio (e/L) from 0.15 to 0.20 resulted in a growth of the average story drift by about $5.23 \%, 1.94 \%$ and $7.27 \%$ for NSC, HSC and VHSC respectively.

For Example-2, increasing the eccentricity ratio (e/L), generally increased the story drift along the height of the building for different concrete strength. The drift response of Example-2 is approximately similar to the result of Example-1. It can be seen that, for Case-II under the artificial earthquake in Egypt, increasing the eccentricity ratio (e/L), generally increased the story drift along the height of the building for different concrete strength. It can be seen that, increasing the eccentricity ratio (e/L) from 0.0 to 0.10 resulted a growth in the average story drift by about $25.92 \%, 29.21 \%$ and $22.58 \%$ for NSC, HSC and VHSC respectively, while increasing the eccentricity ratio (e/L) from 0.10 to 0.15 resulted a growth in the average story drift by about $13.24 \%, 3.20 \%$ and $8.50 \%$ for NSC, HSC and VHSC respectively. Increasing the eccentricity ratio $(\mathrm{e} / \mathrm{L})$ from 0.15 to 0.20 resulted in a growth in the average story drift by about $11.24 \%$, $27.42 \%$ and $25.39 \%$ for NSC, HSC, and VHSC respectively.

\subsection{Effect of (e/L) Ratio on the Story Shear}

As can be seen from Tables 5 to 12, for the studied Example-1 and Example-2, for Case-I and Case-II, increasing the eccentricity ratio $(\mathrm{e} / \mathrm{L})$ resulted in a reduction in the average story shear. This can be attributed to the reduced cross-sections of shear wall $\mathrm{W}_{2}$ of the building as a result of increasing the eccentricity ratio (e/L). For Case-I of Example-1, increasing (e/L) from 0.0 to 0.10 resulted in a reduction in the average story shear by about $1.30 \%, 9.18 \%$ and $11.75 \%$, for NSC, HSC, and VHSC, respectively, while increasing (e/L) from 0.10 to 0.15 resulted in a reduction in the average story shear by about $4.69 \%, 4.93 \%$ and $6.20 \%$, for NSC, HSC, and VHSC, respectively. Increasing (e/L) from 0.15 to 0.20 decreased the average story shear by $11.88 \%$, $11.25 \%$, and $10.73 \%$, respectively. For Case-II of Example-1, increasing (e/L) from 0.0 to 0.10 resulted in a reduction in the average story shear by $1.30 \%, 4.21 \%$, and $6.33 \%$, for NSC, HSC, and VHSC, respectively, while increasing (e/L) from 0.10 to 0.15 resulted in a reduction in the average story shear by $4.49 \%, 4.93 \%$, and $5.36 \%$, for NSC, HSC, and VHSC, respectively. Increasing (e/L) from 0.15 to 0.20 decreased the average story shear by relatively small values $11.88 \%, 5.47 \%$ and $7.61 \%$, respectively. The same trend is observed for Case-I and Case-II of Example-1, under the artificial earthquake of Egypt. For Example-2, the shear response is approximately similar to that of Example-1. For Case-I of Example-2, it can be seen that, increasing $(\mathrm{e} / \mathrm{L})$ from 0.0 to 0.10 resulted in a reduction of the average story shear by about $6.87 \%, 10.91 \%$ and $14.44 \%$ for NSC, HSC and VHSC respectively, while increasing (e/L) from 0.10 to 0.15 resulted in a reduction of the average story shear by about $5.60 \%, 8.35 \%$ and $5.21 \%$ for NSC, HSC and VHSC respectively. Increasing the eccentricity ratio (e/L) from 0.15 to 0.20 resulted in a reduction of the average story shear by about $11.73 \%, 0.71 \%$, and $6.48 \%$, respectively. For Case-II, increasing (e/L) from 0.0 to 0.10 resulted in a reduction of the average story shear by about $6.87 \%, 9.97 \%$ and $13.49 \%$ for NSC, HSC and VHSC respectively, while increasing (e/L) from 0.10 to 0.15 resulted in a reduction of the average story shear by about $5.60 \%, 8.33 \%$ and $5.40 \%$ for NSC, HSC and VHSC respectively, while increasing (e/L) from 0.15 to 0.20 resulted in a reduction of the average story shear by about $11.73 \%, 1.97 \%$ and $4.58 \%$, respectively.

\section{6-EVALUATION OF THE SELF METHODS WHEN APPLIED TO NSC AND HSC MULTISTORY BUILDINGS}

The values of the story shear calculated from the SELF methods of ASCE/SEI 7-16, EC-8 and ECL-2012 for Example-1and Example-2 are compared in Tables 5 to 12 with the values 
calculated under EL Centro and the artificial earthquake of Egypt for the studied different $(\mathrm{e} / \mathrm{L})$ ratio. This comparison showed that the story shear calculated using the SELF method of ASCE/SEI 7-16 and EC-8 are safe and conservative for all concrete strength cases for the studied two examples with different e/L ratio. It should be noted that the story shear forces predicated by SELF methods of ASCE/SEI 7-16 and EC-8 are very conservative for example-2, while for Example-1 these predications were just conservative. The SELF method of ECL-2012 is unconservative for the upper stories of some cases of HSC, and VHSC of Example-1 and conservative for all cases of Example-2 as shown in Table (7) and Table (8). This showed that, the story shear calculated using the SELF method of ECL-2012 may lead to unsafe results when applied to NSC, HSC and VHSC torsionally asymmetric multistory buildings with the studied different $(\mathrm{e} / \mathrm{L})$ ratio.

\section{7-CONCLUSIONS}

Based on the results of this study on the seismic behavior of torsionally asymmetric 3-D multistory buildings constructed from NSC $\left(f_{c}^{\prime}=25 \mathrm{MPa}\right), \mathrm{HSC}\left(f_{c}^{\prime}=75 \mathrm{MPa}\right)$ and VHSC $\left(f_{c}^{\prime}=\right.$ $100 \mathrm{MPa})$ for the studied different $(\mathrm{e} / \mathrm{L})$ ratios $(0.10,0.15$ and 0.20$)$, the following can be concluded:

1) Increasing the design concrete strength from NSC to HSC generally reduces the average story displacement and the average story drift along the height of 3-D torsionally asymmetric multistory buildings for the studied different $(\mathrm{e} / \mathrm{L})$ ratio. Increasing the design concrete strength to VHSC may cause an increase in the average story displacement and the average story drift (compared to the case of HSC) especially in the upper stories because of the mixed action of increasing the concrete strength and the reduction of the columns cross-sections in the upper stories due to the reduction in the column vertical loads.

2) The average story shear generally decreases with increasing the design concrete strength from NSC to VHSC (without a clear trend) for torsionally asymmetric multistory buildings with the studied different $(\mathrm{e} / \mathrm{L})$ ratio.

3) Increasing the studied eccentricity ratio (e/L), generally increases the story displacement and the story drift and reduces the story shear along the height of the studied building examples for different cases of concrete strengths.

4) The limits of the story drift adopted by EC-8, ASCE/SEI 7-16 and ECL-2012 are conservative when applied to NSC, HSC, and VHSC torsionally asymmetric buildings with the studied different $(\mathrm{e} / \mathrm{L})$ ratio.

5) The SELF methods of ASCE/SEI 7-16 and EC-8 are safe and conservative for all the studied cases of NSC, HSC, and VHSC torsionally asymmetric buildings with the studied different (e/L) ratio.

6) The SELF method of ECL-2012 is unconservative for some cases (especially for the upper stories) when applied to NSC, HSC, and VHSC torsionally asymmetric multistory buildings for the studied different (e/L) ratio, and consequently, it is recommended that this method should not be used for these cases.

\section{REFERENCES}

1. International Code Council, (2018). "International Building Code", USA.

2. ASCE/SEI 7-16, (2016). "Minimum Design Loads and Associated Criteria for Buildings and Other Structures", American Society of Civil Engineers, Structural Engineering Institute, No 7-16.

3. European Committee for Standardization, (2003) "Eurocode8: Design of Structures for Earthquake Resistance". CEN-Draft No.6, Brussels.

4. Ministry of Housing, Utilities and Urban Communities. (2012). Egyptian Code for loads and forces in structural works, Cairo, Egypt.

5. Rosenblueth, E. and Meli, R. (1986). "The 1985 Earthquake: Causes and Effects in Mexico City," Concrete International, Vol. 8, No. 5, pp. 23-34. 


\section{SEISMIC BEHAVIOR OF TORSIONALLY ASYMMETRIC NSC AND HSC 3-D MULTISTORY BUILDINGS}

6. Mitchell, D., Tinawi, R. and Redwood, R. G. (1990). "Damage to Buildings due to the 1989 Loma Prieta Earthquake," Canadian Journal of Civil Engineering, Vol. 17, 1990, pp. 813-834.

7. ACI Committee 363, (2011) "Guide to Quality Control and Assurance of High-Strength Concrete", (ACI 363.2R-11)", American concrete Institute, Farmington, Hills, M.I, 48331, $20 \mathrm{P}$.

8. Abd El Rasol, S. E. (2015). "Theoretical Study on Unsymmetrical Arrangement in Plan of Reinforced Concrete Shear Walls for Braced and Unbraced Buildings", M.Sc. Thesis, Civil Engineering Department, Cairo University.

9. Tso, W. K. (1990). "Static Eccentricity Concept For Torsional Moment Estimation". J. Struct. Eng. 1990 ASCE 116:1199-212.

10. Varadharajan, S., Sehgal, V.K. and Saini, B. (2013). "Review of different Structural irregularities in buildings," Journal of Structural Engineering Vol. 39, No. 5, pp. 538-563.

11. Zalka, K. A. (2010). "Torsional Analysis of Multi-Story Building Structures under horizontal load," Struct. Design Tall Spec. Build. 22, 126-14, 2013 Published online 2 December 2010 in Wiley Online Library (wileyonlinelibrary.com). DOI: 10.1002/tal.665.

12. Thaskeen, R. and Shajee, S. (2016). "Torsional Irregularity of Multi-storey Structures". International Journal of Innovative Research in Science, Engineering and Technology (IJIRSET), Vol. 5, Issue 9.

13. Thejesh, T.N. and Chandr, B.S. (2016). "Torsional Response on RC Framed Structures Using Response Spectrum Analysis," International Journal of Engineering Science and Computing.

14. Yousef, A. M. (2004). "Applicability of the Static Equivalent Lateral Force Methods for HSC building Frames and Dual-Systems", Ain Shams Scientific Bulletin, V.39, NO. 3, pp.1-19.

15. Computers and Structures, Inc., ETABS 2017: integrated building design software, Berkeley, California, USA.

16. CSI Computers and Structures INC. (2017). "Introductory Tutorial for E-TABS: Linear and Nonlinear Static and Dynamic Analysis and Design of Three- Dimensional Structures"..

17. Takeda, T., Sozen, M. A. and Nielsen, N. N. (1970). "Reinforced Concrete Response to Simulated Earthquakes," Journal of Structural Division, ASCE, V. 96, No. ST12, pp. 2557-2573.

18. Daniel, C. and Patrick, P. (1995). "Stress-Strain Model for Confined High-Strength Concrete", Journal of Structural Engineering, V. 121, N0. 3, pp. 468-477.

19. ACI Committee 318," Building Code Requirements for Reinforced Concrete and Commentary (ACI 318-14)", American concrete Institute, Farmington, Hills, M.I, 48331.

20. Massicotte, B., Elwi, A. E. and Mac Gregor, I. G. (1990). "Tension-Stiffening Model for Planner Reinforced Concrete Members", Journal of Structural Division, ASCE, V. 116, N0. 11, pp. 3039-3058.

21. Fillippou, F. C. (1986). “A simple Model for Reinforcing Bar Anchorages under Cyclic Excitations", Journal of Sructural Engineering, V. 112, No. 7, pp. 1639-1659.

22. Gasparini, D. A. and Vanmarcke, E. H. (1976). "SIMQKE: A program for Artificial Motion Generation", Massachusetts Institute of Technology, Department of Civil Engineering, A available from NISEE, University of California, Berkeley, California.

23. Paulay, T., Carr, A. J. and Tompkins, D. N. (1980). "Response of Ductile Reinforced Concrete Frames Located in Zone C", Bulletin of the New Zealand National Society for Earthquake Engineering, Vol. 13, No. 3, pp. 209-225. 
SEISMIC BEHAVIOR OF TORSIONALLY ASYMMETRIC NSC AND HSC 3-D MULTISTORY BUILDINGS

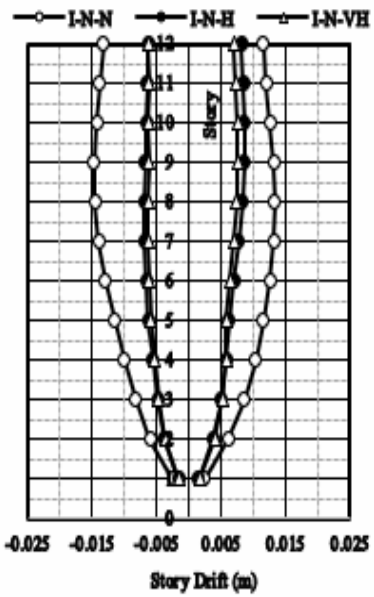

(a) $\mathrm{e} / \mathrm{L}=0.0$

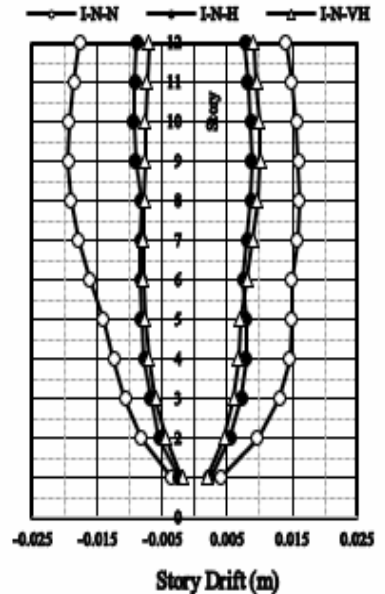

(b) $e / L=0.10$

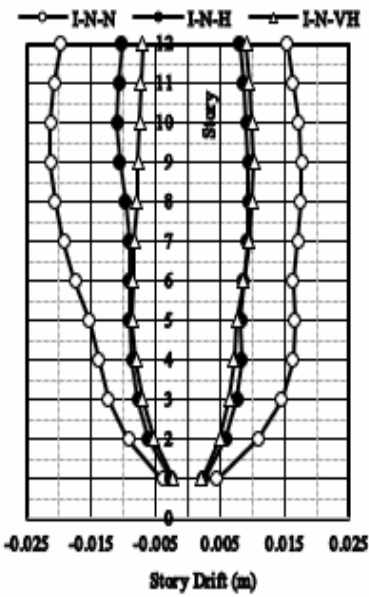

(c) $\mathrm{e} / \mathrm{L}=0.15$

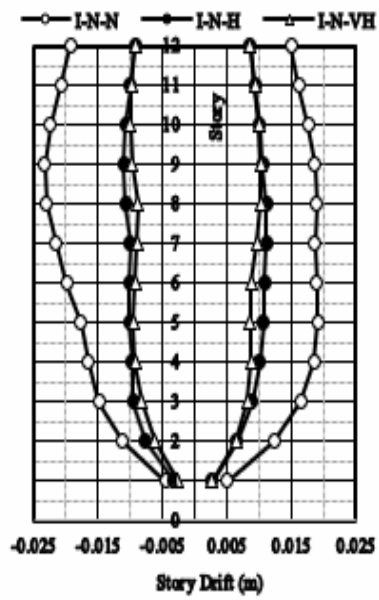

(d) $\mathrm{e} / \mathrm{L}=0.20$

Fig. 6. Story drift response for Case-I of Example-1 under N-S component of EL Centro 1940 earthquake.

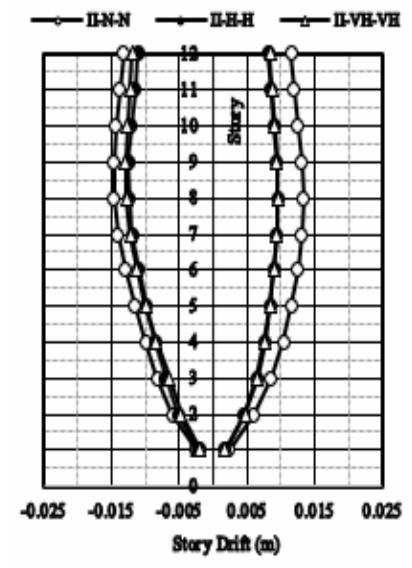

(a) $e / L=0.0$

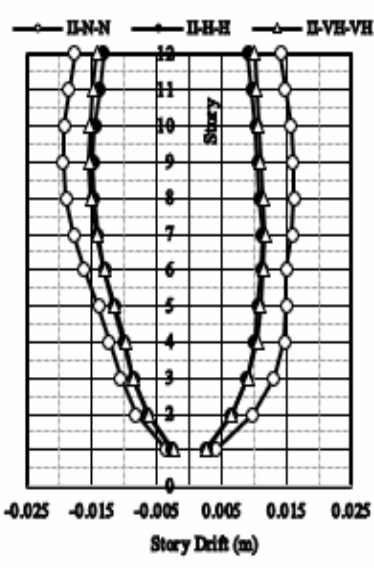

(b) $\mathrm{e} / \mathrm{L}=0.10$

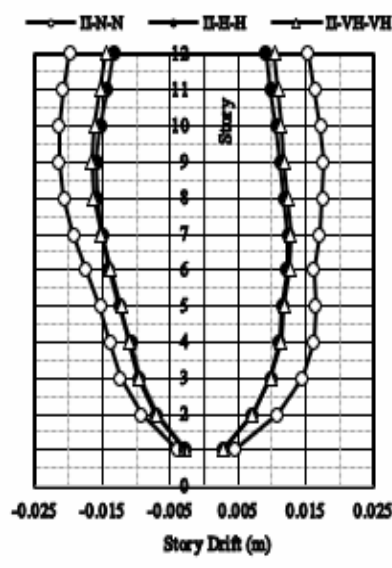

(c) $\mathrm{e} / \mathrm{L}=0.15$

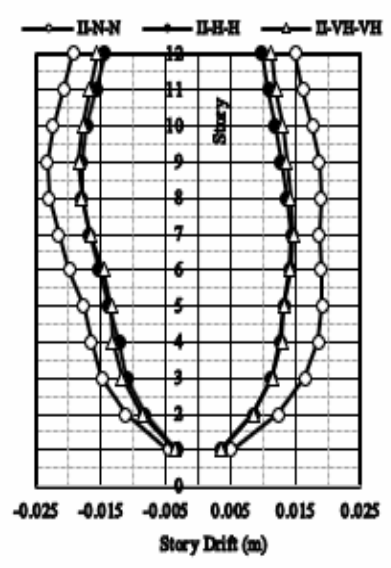

(d) $\mathrm{e} / \mathrm{L}=0.20$

Fig. 7. Story drift response for Case-II of Example-1 under N-S component of EL Centro 1940 earthquake.

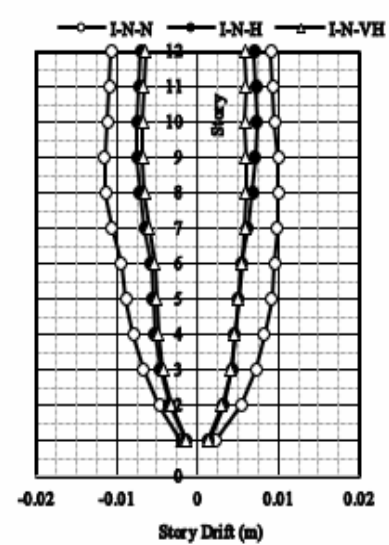

(a) $\mathrm{e} / \mathrm{L}=0.0$

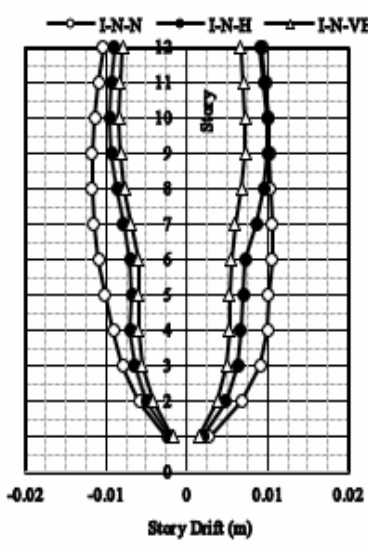

(b) $e / L=0.10$

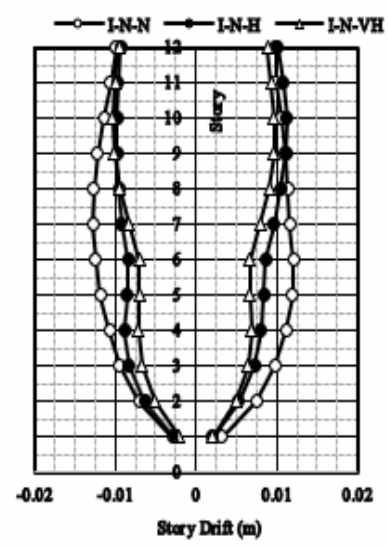

(c) $\mathrm{e} / \mathrm{L}=0.15$

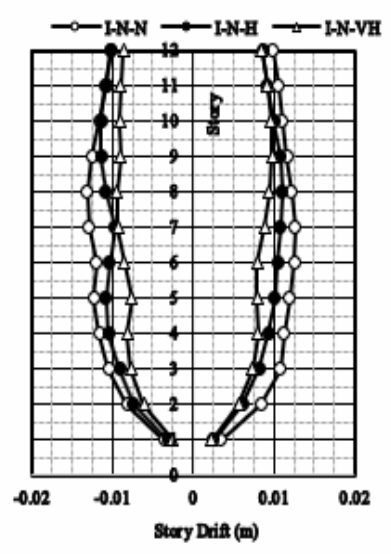

(d) $\mathrm{e} / \mathrm{L}=0.20$

Fig. 8. Story drift response for Case-I of Example-1 under the artificial earthquake of Egypt. 
SEISMIC BEHAVIOR OF TORSIONALLY ASYMMETRIC NSC AND HSC 3-D MULTISTORY BUILDINGS

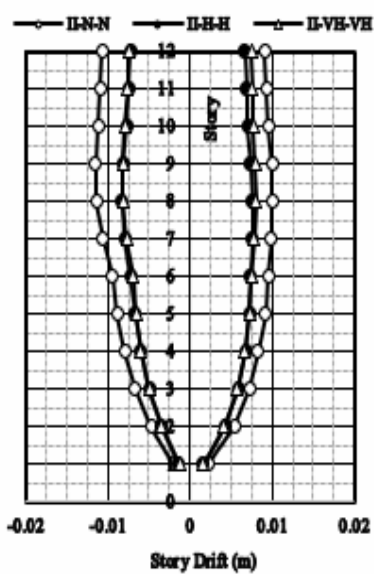

(a) $\mathrm{e} / \mathrm{L}=0.0$

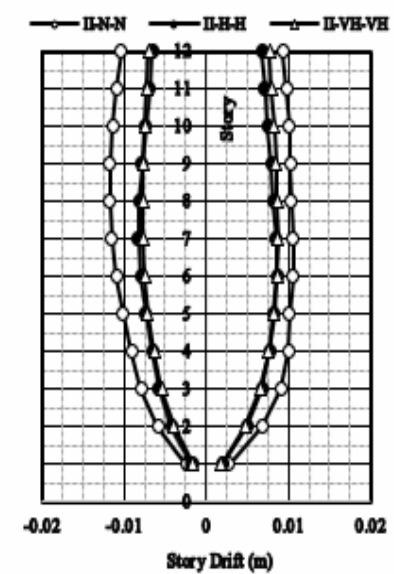

(b) $\mathrm{e} / \mathrm{L}=0.10$

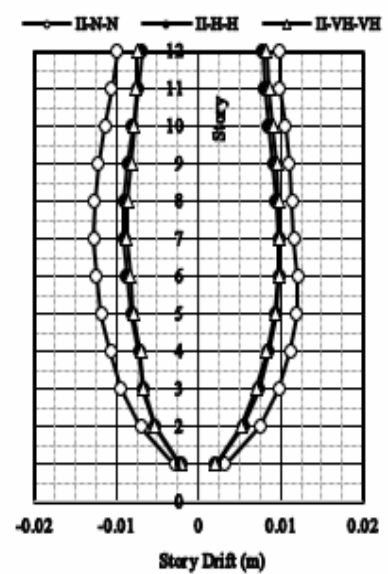

(c) $\mathrm{e} / \mathrm{L}=0.15$

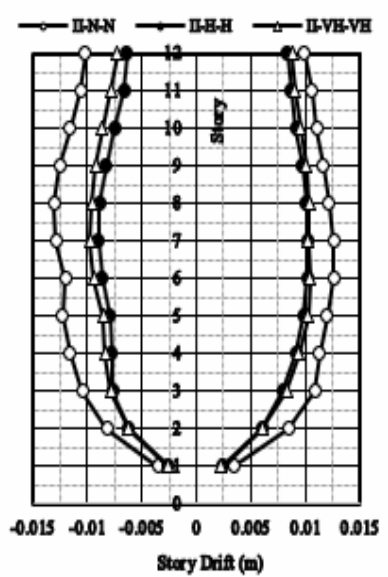

(d) $\mathrm{e} / \mathrm{L}=0.20$

Fig. 9. Story drift response for Case- II of Example-1 under the artificial earthquake of Egypt.

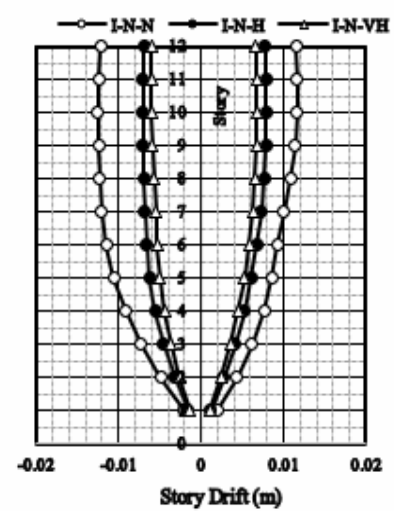

(a) $\mathrm{e} / \mathrm{L}=0.0$

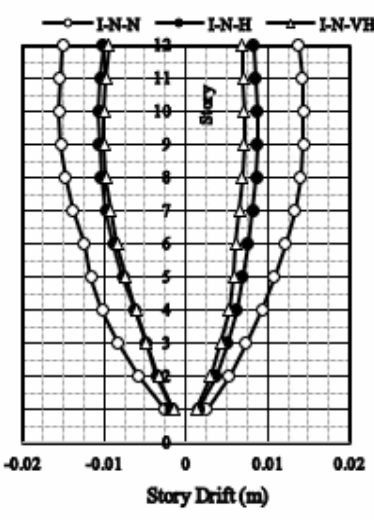

(b) $\mathrm{e} / \mathrm{L}=0.10$

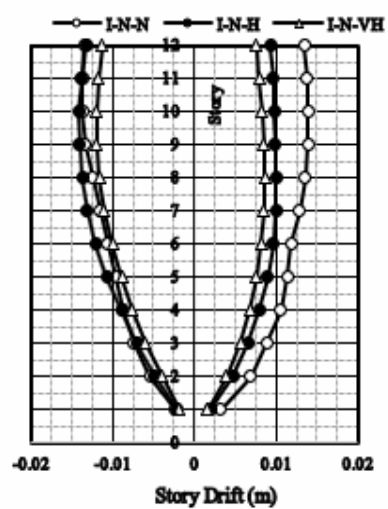

(c) $\mathrm{e} / \mathrm{L}=0.15$

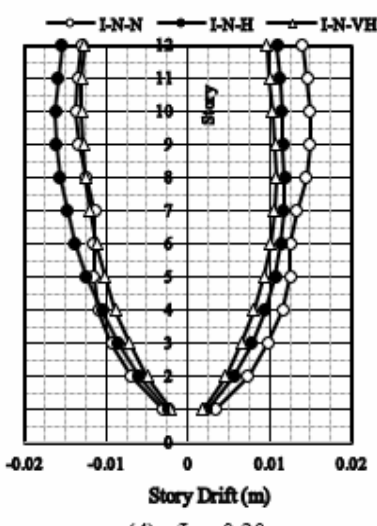

(d) $\mathrm{e} / \mathrm{L}=0.20$

Fig. 10. Story drift response for Case-I of Example-2 under N-S component of EL Centro 1940 earthquake.

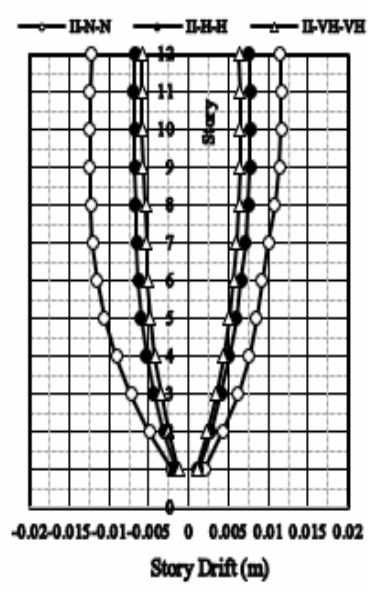

(a) $\mathrm{e} / \mathrm{L}=0.0$

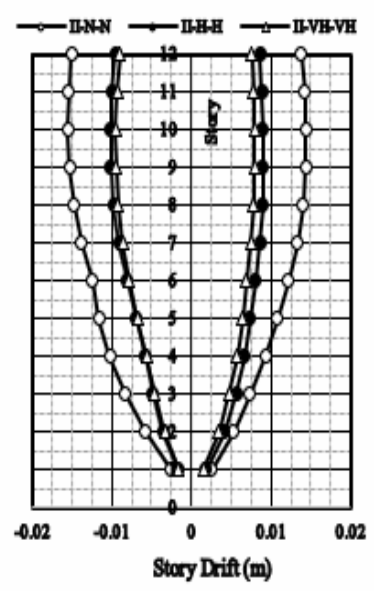

(b) $\mathrm{e} / \mathrm{L}=0.10$

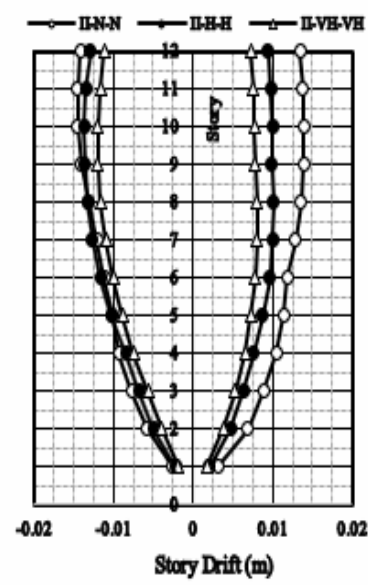

(c) $\mathrm{e} / \mathrm{L}=0.15$

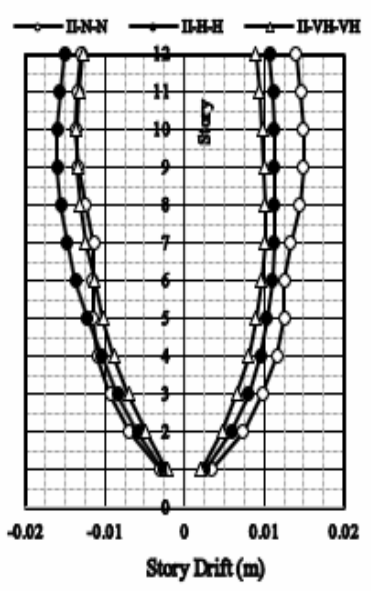

(d) $\mathrm{e} / \mathrm{L}=0.20$

Fig. 11. Story drift response for Case-II of Example-2 under N-S component of EL Centro 1940 earthquake. 
SEISMIC BEHAVIOR OF TORSIONALLY ASYMMETRIC NSC AND HSC 3-D MULTISTORY BUILDINGS

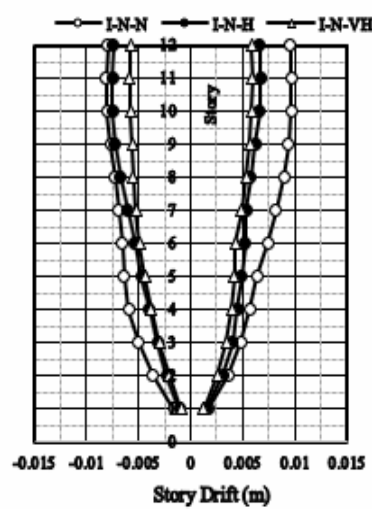

(a) $\mathrm{e} / \mathrm{L}=0.0$

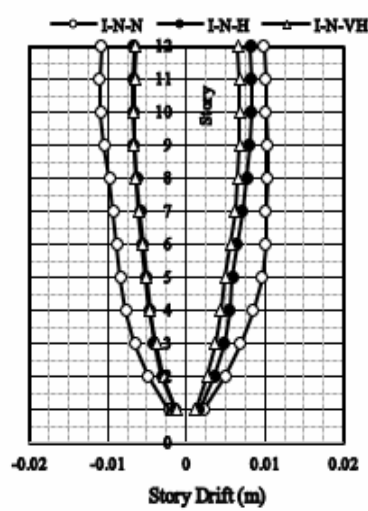

(b) $\mathrm{e} / \mathrm{L}=0.10$

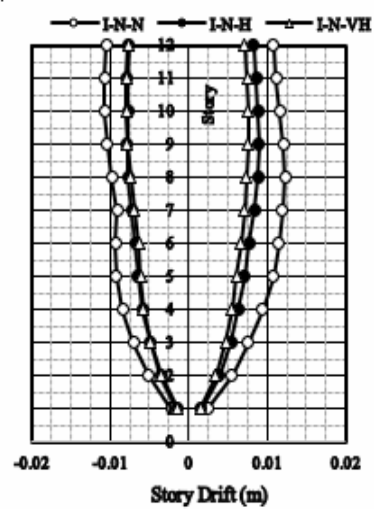

(c) $\mathrm{e} / \mathrm{L}=0.15$

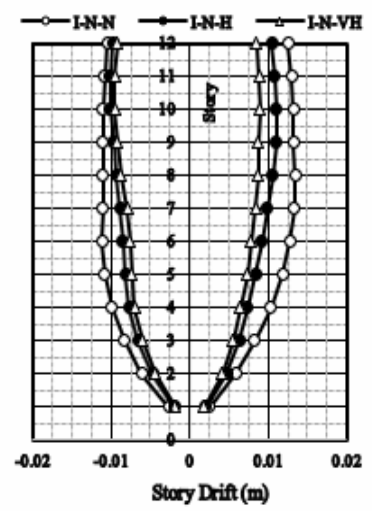

(d) $\mathrm{e} / \mathrm{L}=0.20$

Fig. 12. Story drift response for Case-I of Example-2 under the artificial earthquake of Egypt.

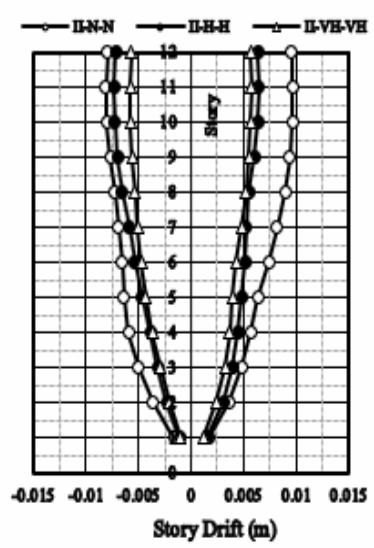

(a) $e / L=0.0$

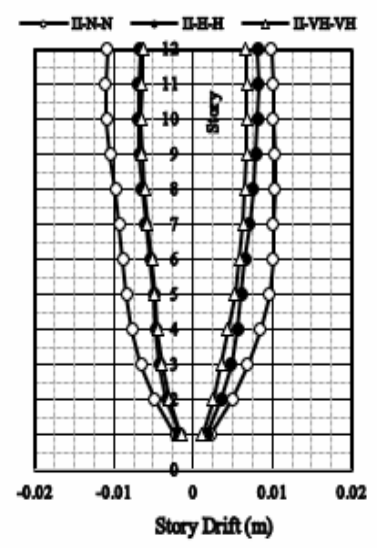

(b) $e / L=0.10$

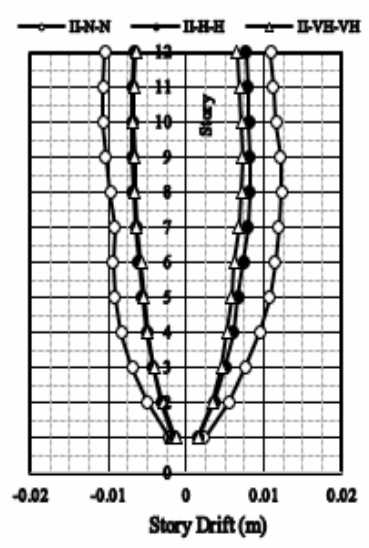

(c) $\mathrm{e} / \mathrm{L}=0.15$

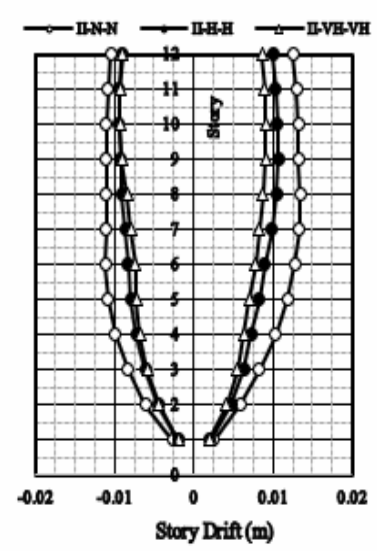

(d) $\mathrm{e} / \mathrm{L}=0.20$

Fig. 13. Story drift response for Case-II of Example-2 under the artificial earthquake of Egypt. 
Table 3. Comparison between the maximum values of the story drift of Example-1 required by ASCE/SEI 7-16, EC-8 and ECL-2012 and that calculating using the dynamic analysis.

\begin{tabular}{|c|c|c|c|c|c|c|}
\hline \multirow[b]{2}{*}{ Case } & \multirow[b]{2}{*}{$e / L$} & \multicolumn{5}{|c|}{ Story drift (m) } \\
\hline & & $\begin{array}{l}\text { EL-Centro } \\
\text { time History }\end{array}$ & $\begin{array}{c}\mathrm{ASCE} / \mathrm{SEI} \\
16\end{array}$ & EC-8 & $\begin{array}{c}\text { Artificial } \\
\text { time History }\end{array}$ & ECL-2012 \\
\hline I-N-N & \multirow{3}{*}{0.00} & 0.01330 & \multirow[t]{24}{*}{0.146} & \multirow[t]{24}{*}{0.0456} & 0.01001 & \multirow[t]{24}{*}{0.0456} \\
\hline I-N-H & & 0.00861 & & & 0.00732 & \\
\hline I-N-VH & & 0.00534 & & & 0.00458 & \\
\hline I-N-N & \multirow{3}{*}{0.10} & 0.01604 & & & 0.01064 & \\
\hline I-N-H & & 0.00879 & & & 0.01003 & \\
\hline I-N-VH & & 0.01001 & & & 0.00727 & \\
\hline $\mathrm{I}-\mathrm{N}-\mathrm{N}$ & \multirow{3}{*}{0.15} & 0.01756 & & & 0.01211 & \\
\hline I-N-H & & 0.00936 & & & 0.01124 & \\
\hline I-N-VH & & 0.01013 & & & 0.00973 & \\
\hline I-N-N & \multirow{3}{*}{0.20} & 0.01903 & & & 0.01262 & \\
\hline I-N-H & & 0.01113 & & & 0.01111 & \\
\hline I-N-VH & & 0.01021 & & & 0.00978 & \\
\hline II-N-N & \multirow{3}{*}{0.00} & 0.01330 & & & 0.01001 & \\
\hline II-H-H & & 0.00961 & & & 0.00765 & \\
\hline II-VH-VH & & 0.00948 & & & 0.00809 & \\
\hline II-N-N & \multirow{3}{*}{0.10} & 0.01604 & & & 0.01064 & \\
\hline II-H-H & & 0.01128 & & & 0.00861 & \\
\hline II-VH-VH & & 0.01168 & & & 0.00881 & \\
\hline II-N-N & \multirow{3}{*}{0.15} & 0.01756 & & & 0.01211 & \\
\hline II-H-H & & 0.01242 & & & 0.00982 & \\
\hline II-VH-VH & & 0.01286 & & & 0.00986 & \\
\hline II-N-N & \multirow{3}{*}{0.20} & 0.01903 & & & 0.01262 & \\
\hline II-H-H & & 0.01435 & & & 0.01017 & \\
\hline II-VH-VH & & 0.01466 & & & 0.01044 & \\
\hline
\end{tabular}

Table 4. Comparison between the maximum values of the story drift of Example-2 required by ASCE/SEI 7-16, EC-8 and ECL-2012 and that calculating using the dynamic analysis.

\begin{tabular}{|c|c|c|c|c|c|c|}
\hline \multirow[b]{2}{*}{ Case } & \multirow[b]{2}{*}{$\mathrm{e} / \mathrm{L}$} & \multicolumn{5}{|c|}{ Story drift (m) } \\
\hline & & $\begin{array}{l}\text { EL-Centro } \\
\text { time History }\end{array}$ & $\begin{array}{c}\mathrm{ASCE} / \mathrm{SEI} 7- \\
16\end{array}$ & $\mathrm{EC}-8$ & $\begin{array}{c}\text { Artificial } \\
\text { time History }\end{array}$ & ECL-2012 \\
\hline $\mathrm{I}-\mathrm{N}-\mathrm{N}$ & \multirow{3}{*}{0.00} & 0.0117 & \multirow{24}{*}{0.120} & \multirow{24}{*}{0.0375} & 0.0097 & \multirow{24}{*}{0.0375} \\
\hline I-N-H & & 0.0079 & & & 0.0067 & \\
\hline I-N-VH & & 0.0014 & & & 0.0046 & \\
\hline $\mathrm{I}-\mathrm{N}-\mathrm{N}$ & \multirow{3}{*}{0.10} & 0.01444 & & & 0.01043 & \\
\hline $\mathrm{I}-\mathrm{N}-\mathrm{H}$ & & 0.00874 & & & 0.00835 & \\
\hline I-N-VH & & 0.00716 & & & 0.00685 & \\
\hline I-N-N & \multirow{3}{*}{0.15} & 0.01398 & & & 0.01227 & \\
\hline $\mathrm{I}-\mathrm{N}-\mathrm{H}$ & & 0.00999 & & & 0.00899 & \\
\hline I-N-VH & & 0.00863 & & & 0.00760 & \\
\hline $\mathrm{I}-\mathrm{N}-\mathrm{N}$ & \multirow{3}{*}{0.20} & 0.01498 & & & 0.01350 & \\
\hline I-N-H & & 0.01181 & & & 0.01106 & \\
\hline I-N-VH & & 0.01078 & & & 0.00894 & \\
\hline II-N-N & \multirow{3}{*}{0.00} & 0.01167 & & & 0.00969 & \\
\hline II-H-H & & 0.00777 & & & 0.00645 & \\
\hline II-VH-VH & & 0.00646 & & & 0.00576 & \\
\hline II-N-N & \multirow{3}{*}{0.10} & 0.01444 & & & 0.01043 & \\
\hline II-H-H & & 0.00904 & & & 0.00831 & \\
\hline II-VH-VH & & 0.00796 & & & 0.00684 & \\
\hline II-N-N & \multirow{3}{*}{0.15} & 0.01398 & & & 0.01227 & \\
\hline II-H-H & & 0.01016 & & & 0.00815 & \\
\hline II-VH-VH & & 0.00807 & & & 0.00719 & \\
\hline II-N-N & \multirow{3}{*}{0.20} & 0.01498 & & & 0.01350 & \\
\hline II-H-H & & 0.01130 & & & 0.01069 & \\
\hline II-VH-VH & & 0.01019 & & & 0.00914 & \\
\hline
\end{tabular}


Table 5. Comparison between the values of the story shear calculated using the SELF method of ASCE/SEI 7-16 and EC8 and that from time history analysis of EL-Centro earthquake for Case-I of Example-1.

\begin{tabular}{|c|c|c|c|c|c|c|c|c|c|c|c|c|c|}
\hline \multirow{2}{*}{ Case } & \multirow{2}{*}{$e / L$} & \multicolumn{12}{|c|}{ Story shear (ton) } \\
\hline & & 12 & 11 & 10 & 9 & 8 & 7 & 6 & 5 & 4 & 3 & 2 & 1 \\
\hline I-N-N & \multirow{5}{*}{0.00} & 61.82 & 94.92 & 105.29 & 123.05 & 132.50 & 135.33 & 132.65 & 133.63 & 151.33 & 179.01 & 209.02 & 220.32 \\
\hline I-N-H & & 65.69 & 99.26 & 113.31 & 115.64 & 117.81 & 98.32 & 112.52 & 138.79 & 166.20 & 195.52 & 211.62 & 212.45 \\
\hline I-N-VH & & 65.02 & 122.44 & 117.54 & 108.85 & 106.84 & 107.30 & 120.88 & 138.58 & 184.69 & 216.37 & 231.65 & 233.07 \\
\hline ASCE/SEI 7-16 & & 66.28 & 129.52 & 186.83 & 237.55 & 282.35 & 320.75 & 353.43 & 379.90 & 400.32 & 414.95 & 424.09 & 428.17 \\
\hline EC-8 & & 69.80 & 137.36 & 199.56 & 255.58 & 306.02 & 350.22 & 388.81 & 421.03 & 446.80 & 466.17 & 479.11 & 485.58 \\
\hline I-N-N & \multirow{5}{*}{0.10} & 50.65 & 83.77 & 118.02 & 142.93 & 147.82 & 133.51 & 129.39 & 131.64 & 141.16 & 172.65 & 191.71 & 213.86 \\
\hline I-N-H & & 50.08 & 77.39 & 98.09 & 104.54 & 110.76 & 94.28 & 95.58 & 129.68 & 156.61 & 176.60 & 194.06 & 208.18 \\
\hline I-N-VH & & 51.32 & 88.00 & 110.45 & 115.04 & 113.60 & 104.12 & 112.48 & 127.05 & 159.02 & 178.79 & 188.55 & 198.82 \\
\hline ASCE/SEI 7-16 & & 66.21 & 129.27 & 186.41 & 236.98 & 281.65 & 319.94 & 352.54 & 378.94 & 399.30 & 413.89 & 423.01 & 427.08 \\
\hline EC-8 & & 69.73 & 137.10 & 199.11 & 254.97 & 305.26 & 349.34 & 387.83 & 419.96 & 445.66 & 464.98 & 477.89 & 484.34 \\
\hline I-N-N & \multirow{5}{*}{0.15} & 55.23 & 95.45 & 111.64 & 131.29 & 141.17 & 132.96 & 128.21 & 126.24 & 129.72 & 155.85 & 177.81 & 193.76 \\
\hline I-N-H & & 51.53 & 80.13 & 90.32 & 98.27 & 99.65 & 95.71 & 91.22 & 122.08 & 145.50 & 174.83 & 197.06 & 195.69 \\
\hline I-N-VH & & 44.28 & 80.15 & 103.87 & 112.37 & 109.35 & 91.47 & 101.29 & 126.55 & 151.28 & 156.37 & 162.43 & 175.82 \\
\hline ASCE/SEI 7-16 & & 66.19 & 129.17 & 186.24 & 236.76 & 281.37 & 319.62 & 352.18 & 378.56 & 398.90 & 413.47 & 422.58 & 426.64 \\
\hline EC-8 & & 69.70 & 136.99 & 198.93 & 254.73 & 304.96 & 348.99 & 387.44 & 419.54 & 445.21 & 464.51 & 477.41 & 483.85 \\
\hline I-N-N & \multirow{3}{*}{0.20} & 36.97 & 67.43 & 90.86 & 107.87 & 118.97 & 126.49 & 128.29 & 122.31 & 134.46 & 148.16 & 156.29 & 153.54 \\
\hline I-N-H & & 43.85 & 70.96 & 79.95 & 90.23 & 92.94 & 93.30 & 111.30 & 118.22 & 123.64 & 136.51 & 141.61 & 159.56 \\
\hline I-N-VH & & 46.66 & 73.48 & 85.71 & 94.78 & 89.98 & 82.00 & 87.36 & 115.98 & 129.20 & 147.85 & 165.91 & 176.67 \\
\hline
\end{tabular}

Table 6. Comparison between the values of the story shear calculated using the SELF method of ASCE/SEI 7-16 and EC8 and that from time history analysis of EL-Centro earthquake for Case-II of Example-1.

\begin{tabular}{|c|c|c|c|c|c|c|c|c|c|c|c|c|c|}
\hline \multirow{2}{*}{ Case } & \multirow{2}{*}{$\mathrm{e} / \mathrm{L}$} & \multicolumn{12}{|c|}{ Story shear (ton) } \\
\hline & & 12 & 11 & 10 & 9 & 8 & 7 & 6 & 5 & 4 & 3 & 2 & 1 \\
\hline$\square \quad-\mathrm{N}-\mathrm{N}$ & \multirow{9}{*}{0.0} & 61.82 & 94.92 & 105.29 & 123.05 & 132.50 & 135.33 & 132.65 & 133.63 & 151.33 & 179.01 & 209.02 & 220.32 \\
\hline$\square-\mathrm{H}-\mathrm{H}$ & & 40.00 & 61.93 & 82.35 & 98.22 & 104.73 & 102.88 & 99.14 & 102.25 & 106.52 & 125.41 & 136.79 & 143.22 \\
\hline$\square \quad-\mathrm{VH}-\mathrm{VH}$ & & 41.95 & 63.98 & 79.58 & 92.67 & 99.75 & 100.27 & 95.70 & 91.57 & 101.24 & 117.60 & 129.39 & 138.19 \\
\hline ASCE/SEI 7-16 (NSC) & & 66.28 & 129.52 & 186.83 & 237.55 & 282.35 & 320.75 & 353.43 & 379.90 & 400.32 & 414.95 & 424.09 & 428.17 \\
\hline ASCE/SEI 7-16 (HSC) & & 62.20 & 121.32 & 174.77 & 222.09 & 263.78 & 299.52 & 329.78 & 354.29 & 373.19 & 386.73 & 395.19 & 398.96 \\
\hline ASCE/SEI 7-16 (VHSC) & & 61.20 & 119.23 & 171.71 & 218.17 & 259.10 & 294.18 & 323.89 & 347.94 & 366.49 & 379.79 & 388.09 & 391.80 \\
\hline EC-8 (NSC) & & 69.80 & 137.36 & 199.56 & 255.58 & 306.02 & 350.22 & 388.81 & 421.03 & 446.80 & 466.17 & 479.11 & 485.58 \\
\hline EC-8 (HSC) & & 65.52 & 128.70 & 186.74 & 239.01 & 285.97 & 327.12 & 362.86 & 392.70 & 416.56 & 434.49 & 446.47 & 452.46 \\
\hline EC-8 (VHSC) & & 64.47 & 126.49 & 183.47 & 234.79 & 280.89 & 321.28 & 356.38 & 385.66 & 409.09 & 426.69 & 438.45 & 444.33 \\
\hline$\square \quad-\mathrm{N}-\mathrm{N}$ & \multirow[t]{5}{*}{0.10} & 50.65 & 83.77 & 118.02 & 142.93 & 147.82 & 133.51 & 129.39 & 131.64 & 141.16 & 172.65 & 191.71 & 213.86 \\
\hline$\square \quad-\mathrm{H}-\mathrm{H}$ & & 39.48 & 66.97 & 82.65 & 91.42 & 100.95 & 99.25 & 99.31 & 96.76 & 99.92 & 109.94 & 127.69 & 138.48 \\
\hline$\square \quad-\mathrm{VH}-\mathrm{VH}$ & & 36.74 & 63.36 & 79.64 & 88.53 & 95.33 & 93.79 & 92.43 & 90.60 & 89.05 & 100.01 & 118.27 & 131.21 \\
\hline ASCE/SEI 7-16 (NSC) & & 66.21 & 129.27 & 186.41 & 236.98 & 281.65 & 319.94 & 352.54 & 378.94 & 399.30 & 413.89 & 423.01 & 427.08 \\
\hline ASCE/SEI 7-16 (HSC) & & 62.12 & 121.05 & 174.33 & 221.51 & 263.07 & 298.69 & 328.87 & 353.30 & 372.14 & 385.64 & 394.07 & 397.83 \\
\hline
\end{tabular}




\begin{tabular}{|c|c|c|c|c|c|c|c|c|c|c|c|c|c|}
\hline ASCE/SEI 7-16 (VH & & 61.12 & 118.96 & 171.27 & 217.57 & 258.37 & 293.33 & 322.95 & 346.93 & 365.42 & 378.67 & 386.95 & 390.64 \\
\hline EC-8 (NSC) & & 69.73 & 137.10 & 199.11 & 254.97 & 305.26 & 349.34 & 387.83 & 419.96 & 445.66 & 464.98 & 477.89 & 484.34 \\
\hline EC-8 (HSC) & & 65.44 & 128.42 & 186.27 & 238.38 & 285.20 & 326.22 & 361.86 & 391.60 & 415.39 & 433.27 & 445.21 & 451.18 \\
\hline EC-8 (VHSC) & & 64.39 & 126.21 & 182.99 & 234.15 & 280.10 & 320.36 & 355.34 & 384.54 & 407.89 & 425.44 & 437.16 & 443.02 \\
\hline$\square \quad-\mathrm{N}-\mathrm{N}$ & \multirow{9}{*}{0.15} & 58.63 & 95.45 & 111.64 & 131.29 & 141.17 & 132.96 & 128.21 & 126.24 & 129.72 & 155.85 & 177.81 & 193.76 \\
\hline$\square \quad-\mathrm{H}-\mathrm{H}$ & & 35.03 & 61.01 & 77.76 & 92.03 & 96.03 & 98.25 & 98.52 & 92.40 & 97.03 & 102.16 & 118.05 & 127.71 \\
\hline$\square \quad-\mathrm{VH}-\mathrm{VH}$ & & 35.35 & 60.00 & 74.56 & 88.34 & 91.76 & 89.71 & 90.62 & 85.55 & 87.28 & 91.75 & 108.17 & 118.06 \\
\hline ASCE/SEI 7-16 (NSC) & & 66.19 & 129.17 & 186.24 & 236.76 & 281.37 & 319.62 & 352.18 & 378.56 & 398.90 & 413.47 & 422.58 & 426.64 \\
\hline ASCE/SEI 7-16 (HSC) & & 62.09 & 120.94 & 174.16 & 221.27 & 262.78 & 298.35 & 328.49 & 352.89 & 371.71 & 385.19 & 393.62 & 397.37 \\
\hline ASCE/SEI 7-16 (VHSC) & & 61.09 & 118.85 & 171.09 & 217.33 & 258.07 & 292.99 & 322.57 & 346.52 & 364.99 & 378.22 & 386.49 & 390.18 \\
\hline EC-8 (NSC) & & 69.70 & 136.99 & 198.93 & 254.73 & 304.96 & 348.99 & 387.44 & 419.54 & 445.21 & 464.51 & 477.41 & 483.85 \\
\hline EC-8 (HSC) & & 65.41 & 128.31 & 186.08 & 238.13 & 284.88 & 325.85 & 361.44 & 391.15 & 414.91 & 432.77 & 444.69 & 450.66 \\
\hline EC-8 (VHSC) & & 64.36 & 126.09 & 182.81 & 233.89 & 279.79 & 319.99 & 354.93 & 384.09 & 407.41 & 424.94 & 436.65 & 442.50 \\
\hline$\square \quad-\mathrm{N}-\mathrm{N}$ & \multirow{9}{*}{0.20} & 36.97 & 67.43 & 90.86 & 107.87 & 118.97 & 126.49 & 128.29 & 122.31 & 134.46 & 148.16 & 156.29 & 153.54 \\
\hline$\square \quad-\mathrm{H}-\mathrm{H}$ & & 29.39 & 53.94 & 75.52 & 89.55 & 93.93 & 94.42 & 95.73 & 89.51 & 91.80 & 93.61 & 107.86 & 120.77 \\
\hline$\square \quad-\mathrm{VH}-\mathrm{VH}$ & & 27.60 & 51.63 & 71.68 & 84.13 & 87.14 & 85.34 & 86.14 & 80.24 & 81.88 & 87.82 & 93.96 & 105.84 \\
\hline ASCE/SEI 7-16 (NSC) & & 66.15 & 129.02 & 186.00 & 236.44 & 280.98 & 319.16 & 351.67 & 378.01 & 398.31 & 412.86 & 421.96 & 426.01 \\
\hline ASCE/SEI 7-16 (HSC) & & 62.05 & 120.79 & 173.90 & 220.92 & 262.35 & 297.86 & 327.95 & 352.31 & 371.09 & 384.55 & 392.96 & 396.71 \\
\hline ASCE/SEI 7-16 (VHSC) & & 61.04 & 118.69 & 170.82 & 216.97 & 257.64 & 292.48 & 322.01 & 345.91 & 364.34 & 377.55 & 385.80 & 389.49 \\
\hline EC-8 (NSC) & & 69.66 & 136.84 & 198.68 & 254.39 & 304.54 & 348.49 & 386.88 & 418.93 & 444.56 & 463.83 & 476.70 & 483.14 \\
\hline EC-8 (HSC) & & 65.37 & 128.14 & 185.81 & 237.75 & 284.42 & 325.31 & 360.85 & 390.50 & 414.22 & 432.04 & 443.95 & 449.90 \\
\hline EC-8 (VHSC) & & 64.31 & 125.92 & 182.52 & 233.50 & 279.31 & 319.44 & 354.31 & 383.41 & 406.69 & 424.18 & 435.87 & 441.71 \\
\hline
\end{tabular}

Table 7. Comparison between the values of the story shear calculated using the SELF method of ECL-2012 and that from time history analysis of the artificial earthquake of Egypt for Case-I of Example-1.

\begin{tabular}{|c|c|c|c|c|c|c|c|c|c|c|c|c|c|}
\hline \multirow{2}{*}{ Case } & \multirow{2}{*}{$e / L$} & \multicolumn{12}{|c|}{ Story shear (ton) } \\
\hline & & 12 & 11 & 10 & 9 & 8 & 7 & 6 & 5 & 4 & 3 & 2 & 1 \\
\hline $\mathrm{I}-\mathrm{N}-\mathrm{N}$ & \multirow{4}{*}{0.00} & 35.85 & 77.52 & 91.83 & 112.07 & 125.61 & 119.55 & 114.09 & 124.84 & 122.78 & 142.00 & 144.75 & 145.27 \\
\hline I-N-H & & 49.92 & 77.69 & 99.10 & 109.13 & 110.07 & 104.33 & 107.55 & 122.59 & 132.83 & 155.68 & 178.74 & 200.61 \\
\hline I-N-VH & & 57.61 & 78.37 & 94.68 & 103.93 & 101.62 & 98.83 & 100.88 & 120.49 & 128.05 & 153.71 & 175.15 & 194.83 \\
\hline ECL-2012 & & 36.56 & 70.07 & 100.94 & 128.73 & 153.79 & 175.72 & 194.89 & 210.87 & 223.65 & 233.29 & 239.71 & 242.92 \\
\hline $\mathrm{I}-\mathrm{N}-\mathrm{N}$ & \multirow{4}{*}{0.10} & 35.07 & 59.53 & 71.40 & 81.84 & 100.53 & 107.73 & 101.92 & 99.20 & 101.75 & 107.90 & 110.07 & 120.02 \\
\hline $\mathrm{I}-\mathrm{N}-\mathrm{H}$ & & 48.16 & 83.05 & 108.43 & 114.36 & 101.89 & 105.58 & 99.95 & 118.57 & 142.83 & 155.34 & 168.59 & 178.92 \\
\hline I-N-VH & & 50.46 & 82.05 & 95.21 & 96.28 & 100.52 & 100.04 & 105.68 & 110.88 & 131.16 & 151.36 & 164.61 & 178.35 \\
\hline ECL-2012 & & 36.46 & 69.88 & 100.67 & 128.37 & 153.37 & 175.24 & 194.37 & 210.31 & 223.06 & 232.67 & 239.07 & 242.27 \\
\hline $\mathrm{I}-\mathrm{N}-\mathrm{N}$ & \multirow{4}{*}{0.15} & 38.92 & 61.92 & 68.44 & 73.82 & 86.83 & 88.96 & 90.18 & 98.90 & 98.63 & 105.70 & 119.06 & 106.82 \\
\hline I-N-H & & 49.02 & 78.94 & 95.22 & 102.65 & 104.96 & 113.04 & 103.88 & 122.36 & 143.18 & 160.47 & 174.99 & 175.10 \\
\hline I-N-VH & & 45.28 & 79.87 & 102.03 & 112.43 & 112.28 & 102.47 & 110.51 & 115.24 & 123.50 & 129.49 & 154.59 & 167.05 \\
\hline ECL-2012 & & 36.42 & 69.80 & 100.56 & 128.24 & 153.20 & 175.05 & 194.16 & 210.08 & 222.82 & 232.42 & 238.81 & 242.01 \\
\hline $\mathrm{I}-\mathrm{N}-\mathrm{N}$ & \multirow{4}{*}{0.20} & 33.52 & 50.96 & 58.59 & 63.89 & 68.22 & 73.49 & 76.74 & 79.15 & 80.10 & 90.54 & 100.05 & 118.85 \\
\hline I-N-H & & 42.35 & 73.68 & 91.43 & 95.60 & 88.75 & 94.88 & 115.35 & 125.83 & 127.74 & 153.21 & 172.90 & 182.47 \\
\hline I-N-VH & & 46.18 & 76.11 & 88.67 & 89.65 & 104.38 & 108.70 & 106.19 & 114.70 & 128.19 & 147.88 & 164.06 & 167.38 \\
\hline ECL-2012 & & 36.36 & 69.69 & 100.40 & 128.04 & 152.96 & 174.77 & 193.85 & 209.75 & 222.47 & 232.05 & 238.44 & 241.64 \\
\hline
\end{tabular}


Table 8. Comparison between the values of the story shear calculated using the SELF method of ECL-2012 and that from time history analysis of the artificial earthquake of Egypt for Case-II of Example-1.

\begin{tabular}{|c|c|c|c|c|c|c|c|c|c|c|c|c|c|}
\hline \multirow{2}{*}{ Case } & \multirow{2}{*}{$e / L$} & \multicolumn{12}{|c|}{ Story shear (ton) } \\
\hline & & 12 & 11 & 10 & 9 & 8 & 7 & 6 & 5 & 4 & 3 & 2 & 1 \\
\hline II-N-N & \multirow{6}{*}{0.00} & 35.85 & 77.52 & 91.83 & 112.07 & 125.61 & 119.55 & 114.09 & 124.84 & 122.78 & 142.00 & 144.75 & 145.27 \\
\hline II-H-H & & 30.61 & 50.87 & 59.47 & 72.39 & 83.51 & 82.44 & 72.21 & 69.69 & 75.00 & 74.45 & 78.94 & 75.04 \\
\hline II-VH-VH & & 31.49 & 49.12 & 54.26 & 68.64 & 78.80 & 76.63 & 67.98 & 69.34 & 70.71 & 75.46 & 78.67 & 75.18 \\
\hline ECL-2012 (NSC) & & 36.36 & 69.69 & 100.40 & 128.04 & 152.96 & 174.77 & 193.85 & 209.75 & 222.47 & 232.05 & 238.44 & 241.63 \\
\hline ECL-2012 (HSC) & & 34.09 & 65.34 & 94.08 & 119.94 & 143.20 & 163.55 & 181.26 & 196.02 & 207.82 & 216.71 & 222.64 & 225.60 \\
\hline ECL-2012 (VHSC) & & 33.57 & 64.35 & 92.65 & 118.11 & 141.02 & 161.07 & 178.50 & 193.03 & 204.65 & 213.41 & 219.25 & 222.17 \\
\hline II-N-N & \multirow{6}{*}{0.10} & 35.07 & 59.53 & 71.40 & 81.84 & 100.53 & 107.73 & 101.92 & 99.20 & 101.75 & 107.90 & 110.07 & 120.02 \\
\hline II-H-H & & 27.32 & 44.09 & 49.50 & 57.61 & 65.52 & 65.30 & 63.57 & 66.99 & 64.24 & 70.87 & 75.03 & 76.98 \\
\hline II-VH-VH & & 26.07 & 41.43 & 46.23 & 53.98 & 62.44 & 61.93 & 63.86 & 61.56 & 60.18 & 69.77 & 74.76 & 75.27 \\
\hline ECL-2012 (NSC) & & 36.46 & 69.88 & 100.67 & 128.37 & 153.37 & 175.24 & 194.37 & 210.31 & 223.06 & 232.67 & 239.07 & 242.27 \\
\hline ECL-2012 (HSC) & & 34.09 & 65.34 & 94.08 & 119.93 & 143.20 & 163.55 & 181.26 & 196.02 & 207.83 & 216.72 & 222.64 & 225.60 \\
\hline ECL-2012 (VHSC) & & 33.47 & 64.15 & 92.36 & 117.75 & 140.58 & 160.56 & 177.95 & 192.44 & 204.03 & 212.76 & 218.58 & 221.49 \\
\hline II-N-N & \multirow{6}{*}{0.15} & 38.92 & 61.92 & 68.44 & 73.82 & 86.83 & 88.96 & 90.18 & 98.90 & 98.63 & 105.70 & 119.06 & 106.82 \\
\hline II-H-H & & 24.16 & 39.16 & 44.14 & 51.52 & 56.85 & 56.08 & 59.25 & 60.77 & 61.41 & 68.22 & 73.52 & 75.69 \\
\hline II-VH-VH & & 23.64 & 36.81 & 39.89 & 46.47 & 51.54 & 53.18 & 55.40 & 54.29 & 56.81 & 64.18 & 67.91 & 75.05 \\
\hline ECL-2012 (NSC) & & 36.42 & 69.80 & 100.56 & 128.24 & 153.20 & 175.05 & 194.16 & 210.08 & 222.82 & 232.42 & 238.81 & 242.01 \\
\hline ECL-2012 ( & & 34.05 & 65.26 & 93.96 & 119.79 & 143.02 & 163.35 & 181.04 & 195.78 & 207.57 & 216.45 & 222.37 & 225.33 \\
\hline ECL-2012 (VHSC) & & 33.43 & 64.07 & 92.24 & 117.60 & 140.40 & 160.36 & 177.73 & 192.20 & 203.77 & 212.49 & 218.30 & 221.21 \\
\hline II-N-N & \multirow{6}{*}{0.20} & 33.52 & 50.96 & 58.59 & 63.89 & 68.22 & 73.49 & 76.74 & 79.15 & 80.10 & 90.54 & 100.05 & 118.85 \\
\hline II-H-H & & 18.54 & 28.50 & 35.19 & 39.56 & 44.61 & 52.68 & 54.80 & 54.67 & 58.75 & 63.53 & 73.32 & 75.21 \\
\hline II-VH-VH & & 17.89 & 27.87 & 33.50 & 41.50 & 46.50 & 51.23 & 54.72 & 54.99 & 58.67 & 61.65 & 69.22 & 75.03 \\
\hline ECL-2012 (NSC) & & 36.36 & 69.69 & 100.40 & 128.04 & 152.96 & 174.77 & 193.85 & 209.75 & 222.47 & 232.05 & 238.44 & 241.64 \\
\hline ECL-2012 (HSC) & & 33.99 & 65.14 & 93.79 & 119.57 & 142.76 & 163.05 & 180.72 & 195.43 & 207.21 & 216.07 & 221.98 & 224.93 \\
\hline ECL-2012 (VHSC) & & 33.37 & 63.95 & 92.06 & 117.37 & 140.14 & 160.05 & 177.38 & 191.83 & 203.38 & 212.08 & 217.88 & 220.78 \\
\hline
\end{tabular}

Table 9. Comparison between the values of the story shear calculated using the SELF method of ASCE/SEI 7-16 and EC8 and that from time history analysis of EL-Centro earthquake for Case-I of Example-2.

\begin{tabular}{|c|c|c|c|c|c|c|c|c|c|c|c|c|c|}
\hline \multirow{2}{*}{ Case } & \multirow{2}{*}{$e / L$} & \multicolumn{12}{|c|}{ Story shear (ton) } \\
\hline & & 12 & 11 & 10 & 9 & 8 & 7 & 6 & 5 & 4 & 3 & 2 & 1 \\
\hline $\mathrm{I}-\mathrm{N}-\mathrm{N}$ & \multirow{3}{*}{0.0} & 76.16 & 131.02 & 160.57 & 170.85 & 170.43 & 207.84 & 237.34 & 257.25 & 265.88 & 293.31 & 342.95 & 375.53 \\
\hline I-N-H & & 132.14 & 199.86 & 197.50 & 170.96 & 176.25 & 177.80 & 212.78 & 247.05 & 315.19 & 391.66 & 444.28 & 476.40 \\
\hline I-N-VH & & 127.43 & 192.08 & 189.27 & 173.15 & 166.86 & 170.19 & 209.27 & 239.93 & 314.29 & 372.30 & 414.05 & 439.42 \\
\hline $\mathrm{I}-\mathrm{N}-\mathrm{N}$ & \multirow{3}{*}{0.10} & 76.61 & 132.22 & 159.84 & 162.49 & 158.72 & 192.17 & 216.62 & 230.98 & 258.11 & 269.35 & 306.60 & 340.60 \\
\hline I-N-H & & 102.16 & 161.09 & 168.58 & 166.19 & 173.65 & 171.94 & 197.77 & 224.31 & 289.09 & 348.67 & 383.59 & 412.17 \\
\hline I-N-VH & & 93.66 & 146.45 & 151.52 & 146.82 & 164.70 & 181.85 & 213.42 & 226.03 & 262.61 & 307.60 & 336.38 & 342.84 \\
\hline $\mathrm{I}-\mathrm{N}-\mathrm{N}$ & \multirow{3}{*}{0.15} & 71.59 & 124.79 & 152.67 & 156.79 & 157.06 & 166.24 & 180.09 & 226.93 & 255.97 & 262.85 & 289.90 & 319.09 \\
\hline I-N-H & & 80.43 & 134.09 & 165.18 & 174.88 & 195.93 & 199.07 & 224.30 & 237.27 & 241.83 & 282.57 & 311.58 & 318.35 \\
\hline I-N-VH & & 70.06 & 123.77 & 154.78 & 166.35 & 167.34 & 201.56 & 220.57 & 220.21 & 236.05 & 275.21 & 302.02 & 301.82 \\
\hline $\mathrm{I}-\mathrm{N}-\mathrm{N}$ & \multirow{3}{*}{0.20} & 61.31 & 106.77 & 129.45 & 133.56 & 135.14 & 125.74 & 130.78 & 157.05 & 202.56 & 255.88 & 312.36 & 336.01 \\
\hline I-N-H & & 74.84 & 137.37 & 179.45 & 200.87 & 204.28 & 216.54 & 233.91 & 232.68 & 234.89 & 250.90 & 270.90 & 310.63 \\
\hline I-N-VH & & 68.90 & 121.56 & 151.01 & 169.19 & 181.63 & 201.61 & 211.14 & 206.74 & 204.87 & 236.50 & 255.87 & 272.65 \\
\hline ASCE/SEI 7-16 & & 165.02 & 328.34 & 475.29 & 606.39 & 721.75 & 821.25 & 905.35 & 974.24 & 1028.03 & 1067.25 & 1092.34 & 1103.97 \\
\hline EC-8 & & 165.49 & 330.83 & 481.13 & 616.77 & 737.66 & 843.43 & 934.34 & 1010.30 & 1071.07 & 1116.76 & 1147.31 & 1162.58 \\
\hline
\end{tabular}


Table 10. Comparison between the values of the story shear calculated using the SELF method of ASCE/SEI 7-16 and EC-8 and that from time history analysis of EL-Centro earthquake for Case-II of Example-2.

\begin{tabular}{|c|c|c|c|c|c|c|c|c|c|c|c|c|c|}
\hline \multirow{2}{*}{ Case } & \multirow{2}{*}{$e / L$} & \multicolumn{12}{|c|}{ Story shear (ton) } \\
\hline & & 12 & 11 & 10 & 9 & 8 & 7 & 6 & 5 & 4 & 3 & 2 & 1 \\
\hline II-N-N & \multirow{3}{*}{0.0} & 76.16 & 131.02 & 160.57 & 170.85 & 170.43 & 207.84 & 237.34 & 257.25 & 265.88 & 293.31 & 342.95 & 375.53 \\
\hline II-H-H & & 128.92 & 193.84 & 191.41 & 168.04 & 168.16 & 168.61 & 202.95 & 235.97 & 307.57 & 380.34 & 430.23 & 460.98 \\
\hline II-VH-VH & & 120.79 & 180.26 & 177.06 & 161.33 & 156.25 & 164.37 & 200.28 & 227.37 & 294.65 & 346.27 & 383.04 & 406.51 \\
\hline II-N-N & \multirow{3}{*}{0.10} & 76.61 & 132.22 & 159.84 & 162.49 & 158.72 & 192.17 & 216.62 & 230.98 & 258.11 & 269.35 & 306.60 & 340.60 \\
\hline II-H-H & & 104.14 & 161.56 & 166.60 & 160.90 & 163.23 & 161.50 & 189.66 & 215.06 & 282.58 & 341.28 & 384.36 & 403.49 \\
\hline II-VH-VH & & 90.68 & 140.25 & 144.74 & 137.30 & 151.44 & 172.86 & 201.46 & 210.64 & 251.31 & 295.10 & 319.83 & 322.42 \\
\hline II-N-N & \multirow{3}{*}{0.15} & 71.59 & 124.79 & 152.67 & 156.79 & 157.06 & 166.24 & 180.09 & 226.93 & 255.97 & 262.85 & 289.90 & 319.09 \\
\hline II-H-H & & 81.02 & 126.12 & 155.38 & 164.84 & 182.26 & 185.26 & 213.38 & 227.74 & 248.53 & 285.60 & 308.09 & 328.35 \\
\hline II-VH-VH & & 64.01 & 113.71 & 144.52 & 157.67 & 156.80 & 185.43 & 208.30 & 212.36 & 217.11 & 255.93 & 279.65 & 310.77 \\
\hline II-N-N & \multirow{3}{*}{0.20} & 61.31 & 106.77 & 129.45 & 133.56 & 135.14 & 125.74 & 130.78 & 157.05 & 202.56 & 255.88 & 312.36 & 336.01 \\
\hline II-H-H & & 70.82 & 130.46 & 172.09 & 194.11 & 197.44 & 205.16 & 226.73 & 230.30 & 220.45 & 233.89 & 268.43 & 307.38 \\
\hline II-VH-VH & & 63.01 & 111.15 & 149.08 & 172.16 & 180.37 & 190.14 & 202.52 & 200.91 & 189.62 & 211.48 & 247.03 & 283.09 \\
\hline ASCE/SEI 7-16 (NSC) & & 165.64 & 329.52 & 476.97 & 608.52 & 724.28 & 824.12 & 908.50 & 977.63 & 1031.61 & 1070.96 & 1096.13 & 1107.80 \\
\hline ASCE/SEI 7-16 (HSC) & & 162.30 & 320.28 & 462.41 & 589.22 & 700.82 & 797.08 & 878.44 & 945.10 & 997.15 & 1035.10 & 1059.38 & 1070.64 \\
\hline ASCE/SEI 7-16 (VHSC) & & 160.82 & 316.17 & 455.94 & 580.66 & 690.43 & 785.09 & 865.11 & 930.68 & 981.88 & 1019.20 & 1043.08 & 1054.16 \\
\hline EC-8 (NSC) & & 166.11 & 332.02 & 482.84 & 618.94 & 740.24 & 846.38 & 937.60 & 1013.82 & 1074.79 & 1120.64 & 1151.29 & 1166.61 \\
\hline EC-8 (HSC) & & 162.79 & 322.73 & 468.13 & 599.34 & 716.29 & 818.64 & 906.60 & 980.10 & 1038.91 & 1083.13 & 1112.70 & 1127.48 \\
\hline EC-8 (VHSC) & & 161.31 & 318.60 & 461.59 & 590.65 & 705.68 & 806.34 & 892.86 & 965.16 & 1023.00 & 1066.50 & 1095.58 & 1110.12 \\
\hline
\end{tabular}

Table 11. Comparison between the values of the story shear calculated using the SELF method of ECL-2012 and that from time history analysis of the artificial earthquake of Egypt for Case-I of Example-2.

\begin{tabular}{|c|c|c|c|c|c|c|c|c|c|c|c|c|c|}
\hline \multirow{2}{*}{ Case } & \multirow{2}{*}{$e / L$} & \multicolumn{12}{|c|}{ Story shear (ton) } \\
\hline & & 12 & 11 & 10 & 9 & 8 & 7 & 6 & 5 & 4 & 3 & 2 & 1 \\
\hline $\mathrm{I}-\mathrm{N}-\mathrm{N}$ & \multirow{3}{*}{0.0} & 76.03 & 114.84 & 127.36 & 130.42 & 128.15 & 141.85 & 145.08 & 189.11 & 225.90 & 248.98 & 258.54 & 265.42 \\
\hline I-N-H & & 77.81 & 137.80 & 172.62 & 183.32 & 172.76 & 156.19 & 178.70 & 215.34 & 226.81 & 247.42 & 267.30 & 291.22 \\
\hline I-N-VH & & 73.45 & 127.35 & 155.40 & 160.50 & 150.01 & 155.18 & 188.85 & 216.44 & 220.70 & 243.27 & 256.92 & 284.89 \\
\hline I-N-N & \multirow{3}{*}{0.10} & 65.49 & 97.06 & 112.97 & 118.80 & 124.13 & 138.72 & 135.55 & 171.12 & 195.30 & 209.63 & 217.62 & 230.29 \\
\hline I-N-H & & 65.33 & 114.16 & 140.30 & 145.18 & 132.29 & 139.59 & 168.73 & 201.80 & 212.81 & 202.61 & 236.86 & 257.99 \\
\hline I-N-VH & & 66.50 & 112.41 & 132.51 & 131.31 & 119.19 & 132.57 & 167.83 & 193.43 & 199.85 & 201.95 & 234.72 & 270.78 \\
\hline I-N-N & \multirow{3}{*}{0.15} & 58.05 & 83.96 & 97.39 & 106.32 & 118.98 & 127.37 & 130.73 & 140.18 & 147.23 & 160.81 & 182.33 & 189.10 \\
\hline I-N-H & & 64.12 & 107.04 & 124.14 & 125.93 & 120.84 & 139.12 & 155.86 & 185.07 & 195.35 & 183.89 & 228.86 & 257.64 \\
\hline I-N-VH & & 71.18 & 117.97 & 134.16 & 131.19 & 121.07 & 127.95 & 152.77 & 170.83 & 180.72 & 201.96 & 224.36 & 253.70 \\
\hline I-N-N & \multirow{3}{*}{0.20} & 39.41 & 66.15 & 83.16 & 88.20 & 94.40 & 103.20 & 110.98 & 128.58 & 150.03 & 147.15 & 164.61 & 188.39 \\
\hline I-N-H & & 65.92 & 106.49 & 126.32 & 132.24 & 123.86 & 119.63 & 126.31 & 153.62 & 165.40 & 188.41 & 220.86 & 228.52 \\
\hline I-N-VH & & 64.63 & 113.08 & 140.12 & 148.27 & 140.97 & 122.49 & 137.16 & 152.29 & 175.13 & 206.46 & 219.48 & 224.65 \\
\hline ECL-2012 & & 89.59 & 171.71 & 246.36 & 313.91 & 373.96 & 426.49 & 471.76 & 509.49 & 539.67 & 562.43 & 577.60 & 585.19 \\
\hline
\end{tabular}


Table 12. Comparison between the values of the story shear calculated using the SELF method of ECL-2012 and that from time history analysis of the artificial earthquake for Case-II of Example-2.

\begin{tabular}{|c|c|c|c|c|c|c|c|c|c|c|c|c|c|}
\hline \multirow{2}{*}{ Case } & \multirow{2}{*}{$e / L$} & \multicolumn{12}{|c|}{ Story shear (ton) } \\
\hline & & 12 & 11 & 10 & 9 & 8 & 7 & 6 & 5 & 4 & 3 & 2 & 1 \\
\hline II-N-N & \multirow{3}{*}{0.0} & 76.03 & 114.84 & 127.36 & 130.42 & 128.15 & 141.85 & 145.08 & 189.11 & 225.90 & 248.98 & 258.54 & 265.42 \\
\hline II-H-H & & 75.92 & 133.19 & 166.00 & 175.47 & 164.56 & 152.02 & 175.82 & 210.51 & 221.04 & 240.47 & 250.89 & 271.40 \\
\hline II-VH-VH & & 68.59 & 117.46 & 142.58 & 146.84 & 140.05 & 144.31 & 179.52 & 204.30 & 207.71 & 226.15 & 246.20 & 275.90 \\
\hline II-N-N & \multirow{3}{*}{0.10} & 65.49 & 97.06 & 112.97 & 118.80 & 124.13 & 138.72 & 135.55 & 171.12 & 195.30 & 209.63 & 217.62 & 230.29 \\
\hline II-H-H & & 62.18 & 107.98 & 132.81 & 138.27 & 127.45 & 133.57 & 166.73 & 197.23 & 206.17 & 199.36 & 223.41 & 254.32 \\
\hline II-VH-VH & & 65.74 & 111.74 & 134.03 & 135.56 & 121.46 & 129.88 & 162.87 & 185.55 & 189.54 & 194.81 & 229.29 & 264.37 \\
\hline II-N-N & \multirow{3}{*}{0.15} & 58.05 & 83.96 & 97.39 & 106.32 & 118.98 & 127.37 & 130.73 & 140.18 & 147.23 & 160.81 & 182.33 & 189.10 \\
\hline II-H-H & & 63.47 & 106.78 & 125.33 & 122.17 & 116.38 & 130.01 & 155.77 & 183.72 & 193.81 & 184.30 & 218.53 & 259.18 \\
\hline II-VH-VH & & 66.81 & 110.29 & 126.31 & 118.44 & 106.07 & 118.28 & 140.89 & 165.31 & 180.72 & 179.53 & 193.25 & 242.52 \\
\hline II-N-N & \multirow{3}{*}{0.20} & 39.41 & 66.15 & 83.16 & 88.20 & 94.40 & 103.20 & 110.98 & 128.58 & 150.03 & 147.15 & 164.61 & 188.39 \\
\hline II-H-H & & 63.90 & 103.86 & 114.54 & 115.13 & 106.10 & 107.22 & 120.03 & 152.27 & 168.42 & 178.76 & 206.97 & 215.67 \\
\hline II-VH-VH & & 58.99 & 100.90 & 122.53 & 127.27 & 119.99 & 105.67 & 121.95 & 155.25 & 174.04 & 183.84 & 209.10 & 213.24 \\
\hline ECL-2012 (NSC) & & 89.59 & 171.71 & 246.36 & 313.91 & 373.96 & 426.49 & 471.76 & 509.49 & 539.67 & 562.43 & 577.60 & 585.19 \\
\hline ECL-2012 (HSC) & & 86.46 & 165.71 & 237.76 & 302.96 & 360.92 & 411.64 & 455.34 & 491.76 & 520.90 & 542.87 & 557.52 & 564.84 \\
\hline ECL-2012 (VHSC) & & 85.07 & 163.06 & 233.94 & 298.13 & 355.19 & 405.11 & 448.15 & 484.01 & 512.70 & 534.33 & 548.74 & 555.95 \\
\hline
\end{tabular}

